Article

\title{
Catalytic Dry Reforming and Cracking of Ethylene for Carbon Nanofilaments and Hydrogen Production Using a Catalyst Derived from a Mining Residue
}

\author{
Abir Azara ${ }^{1,2}$, El-Hadi Benyoussef ${ }^{2}$, , Faroudja Mohellebi ${ }^{2}$, Mostafa Chamoumi ${ }^{1}$, \\ François Gitzhofer ${ }^{1}$ and Nicolas Abatzoglou ${ }^{1, *(D)}$ \\ 1 Department of Chemical \& Biotechnological Engineering, Université de Sherbrooke, 2500 Boulevard de \\ l’Université, Sherbrooke, QC J1K 2R1, Canada; abir.azara@usherbrooke.ca (A.A.); \\ Mostafa.Chamoumi@USherbrooke.ca (M.C.); francois.gitzhofer@usherbrooke.ca (F.G.) \\ 2 Laboratoire de Valorisation des Énergies Fossiles, École National Polytechnique, 10 Avenue Hassen Badi El \\ Harrach BP182, Alger 16200, Algeria; el-hadi.benyoussef@enp.edu.dz (E.-H.B.); \\ mohellebifaroudja@yahoo.fr (F.M.) \\ * Correspondence: Nicolas.Abatzoglou@USherbrooke.ca
}

Received: 7 November 2019; Accepted: 9 December 2019; Published: 14 December 2019

\begin{abstract}
In this study, iron-rich mining residue (UGSO) was used as a support to prepare a new $\mathrm{Ni}$-based catalyst via a solid-state reaction protocol. Ni-UGSO with different Ni weight percentages wt.\% (5, 10, and 13) were tested for $\mathrm{C}_{2} \mathrm{H}_{4}$ dry reforming (DR) and catalytic cracking (CC) after activation with $\mathrm{H}_{2}$. The reactions were conducted in a differential fixed-bed reactor at $550-750{ }^{\circ} \mathrm{C}$ and standard atmospheric pressure, using $0.5 \mathrm{~g}$ of catalyst. Pure gases were fed at a molar ratio of $\mathrm{C}_{2} \mathrm{H}_{4} / \mathrm{CO}_{2}=3$ for the $\mathrm{DR}$ reaction and $\mathrm{C}_{2} \mathrm{H}_{4} / \mathrm{Ar}=3$ for the $\mathrm{CC}$ reaction. The flow rate is defined by a GHSV $=4800 \mathrm{mLSTP} / \mathrm{h}$.g cat. The catalyst performance is evaluated by calculating the $\mathrm{C}_{2} \mathrm{H}_{4}$ conversion as well as carbon and $\mathrm{H}_{2}$ yields. All fresh, activated, and spent catalysts, as well as deposited carbon, were characterized by Brunauer-Emmett-Teller (BET), X-ray diffraction (XRD), scanning electron microscopy (SEM), energy dispersive X-ray spectrometry (EDX), transmission electron microscopy (TEM), temperature programmed reduction (TPR), and thermogravimetric analysis (TGA). The results so far show that the highest carbon and $\mathrm{H}_{2}$ yields are obtained with $\mathrm{Ni}-\mathrm{UGSO} 13 \%$ at $750{ }^{\circ} \mathrm{C}$ for the $\mathrm{CC}$ reaction and at $650^{\circ} \mathrm{C}$ for the DR reaction. The deposited carbon was found to be filamentous and of various sizes (i.e., diameters and lengths). The analyses of the results show that iron is responsible for the growth of carbon nanofilaments (CNF) and nickel is responsible for the split of $\mathrm{C}-\mathrm{C}$ bonds. In terms of conversion and yield efficiencies, the performance of the catalytic formulations tested is proven at least equivalent to other Ni-based catalyst performances described by the literature.
\end{abstract}

Keywords: dry reforming; catalytic cracking; ethylene; carbon nanofilaments; hydrogen

\section{Introduction}

Hydrogen is an energy vector and is mainly used in the synthesis of several chemicals such as methanol, ammonia, and liquid hydrocarbons via the Fischer-Tropsch process. Concerning carbon nanofilaments (CNF), several studies have shown that they have noteworthy properties, including high surface area, high mechanical resistance, and high electrical and thermal conductivities [1]. This is why research efforts have focused on optimizing and controlling the formation of these types of carbon structures, instead of inhibiting their growth [2]. Although, usually, carbon formation on catalysts causes the deactivation of the catalyst [3], CNF are shown to grow in such a way that the catalytically active sites maintain their activity [4]. CNF properties make them a good substitute to high-cost materials used currently in various applications such as reinforcement of composites [5], manufacturing 
of double-layer condensers [6], fabrication of anodes in lithium batteries [7,8], adsorption [9], support for catalysts [10], or catalysts themselves [11].

$\mathrm{H}_{2}$ is generated mainly from hydrocarbons via thermocatalytic processes such as steam reforming (SR), autothermal reforming (ATR), partial oxidation (POX), dry reforming (DR), and catalytic decomposition or cracking (CC) [12]. However, methane SR is the only industrial production technology used so far [13]. SR is an endothermic reaction and requires a high energy input. Temperatures as high as $950{ }^{\circ} \mathrm{C}$ and relatively high steam/C ratios are required to reach high $\mathrm{H}_{2}$ yields and avoid carbon formation and, consequently, premature catalyst deactivation. In the last decade, many researches have focused on DR that uses $\mathrm{CO}_{2}$ instead of $\mathrm{H}_{2} \mathrm{O}$ to produce not only $\mathrm{H}_{2}$ but also CNF. Hence, DR reaction has not only economic interests but also an environmental interest, which is the contribution on the sequestration of $\mathrm{CO}_{2}$-a greenhouse gas [14-17].

The feedstock composition, the choice of catalysts including the support and active metals, as well as the operating conditions, especially the temperature, are the main elements that have been largely studied to optimize $\mathrm{H}_{2}$ and CNF production [18]. Methane [19-21], n-octane [22], ethanol [15], and biogas [23] are the main reactants used. The use of pyrolytically-produced gases has rarely been cited in the current literature. Arena et al. [24] have developed an innovative process for mass production of multiwall carbon nanotubes (MWCNT) by pyrolysis of virgin or recycled polyolefins. Regarding CNF production, the literature is rather scarce. Svinterekos et al. [25] used lignin (a natural polymer found in plants) combined with recycled polyethylene terephthalate (PET) to make precursor fibers that are used for the electrospinning of CNF. The work presented here is part of a larger research endeavor aimed at the conversion of waste plastic streams into added plus-value products such as CNF. Since the gases produced by plastic pyrolysis are composed mainly of unsaturated hydrocarbons, the first step of this study is focused on using $\mathrm{C}_{2} \mathrm{H}_{4}$ as a surrogate molecule. The dry reforming reaction of ethylene is not yet well reported in the literature; the products of this type of reaction are considerably dependent on the nature of the catalyst used. In the presence of a transition metal catalyst, carbon and synthesis gas are the products obtained from ethylene DR [26]. However, the Mn and Cr oxides convert ethylene to butadiene and propylene. For example, with a $\mathrm{MnO} / \mathrm{SiO}_{2}$ catalyst at $850{ }^{\circ} \mathrm{C}$, the products obtained are $\mathrm{C}_{4} \mathrm{H}_{6}$ with a selectivity of $25 \%, \mathrm{C}_{3} \mathrm{H}_{6}$ with a selectivity of $18 \%$, and traces of $\mathrm{CH}_{4}, \mathrm{C}_{3} \mathrm{H}_{8}$, and $\mathrm{C}_{4} \mathrm{H}_{8}$ [26].

The theoretical reaction of ethylene DR is given by Equation (1) below [26]:

$$
\mathrm{C}_{2} \mathrm{H}_{4}+2 \mathrm{CO}_{2} \rightarrow 4 \mathrm{CO}+2 \mathrm{H}_{2}\left(\Delta \mathrm{H}_{298}^{\circ}=292.5 \mathrm{MJ} / \mathrm{kmol}\right)
$$

Other known reactions that take place during ethylene DR are Equations (2)-(5):

$$
\text { Ethylene decomposition: } \mathrm{C}_{2} \mathrm{H}_{4} \rightarrow 2 \mathrm{C}+2 \mathrm{H}_{2}\left(\Delta \mathrm{H}^{\circ} 298=-52.5 \mathrm{MJ} / \mathrm{kmol}\right)
$$

Reverse water gas shift reaction (RWGS): $\mathrm{CO}_{2}+\mathrm{H}_{2} \rightleftharpoons \mathrm{CO}+\mathrm{H}_{2} \mathrm{O}\left(\Delta \mathrm{H}^{\circ}{ }_{298}=41.0 \mathrm{MJ} / \mathrm{kmol}\right)$

$$
\begin{aligned}
& \text { Boudouard reaction: } 2 \mathrm{CO} \rightleftharpoons \mathrm{CO}_{2}+\mathrm{C}\left(\Delta \mathrm{H}^{\circ}{ }_{298}=-172.0 \mathrm{MJ} / \mathrm{kmol}\right) \\
& \text { Carbon gasification: } \mathrm{C}+\mathrm{H}_{2} \mathrm{O} \rightarrow \mathrm{CO}+\mathrm{H}_{2}\left(\Delta \mathrm{H}^{\circ}{ }_{298}=131.3 \mathrm{MJ} / \mathrm{kmol}\right)
\end{aligned}
$$

In general, at the temperatures used for these reactions and in the presence of the chosen catalysts, hydrocarbon molecules (HC) are converted into free radicals in the gas phase or at the catalyst's surface (intermediates). The reforming agent, $\mathrm{CO}_{2}$ in the case of $\mathrm{DR}$, is also dissociated into oxygen intermediates $\left(\mathrm{O}^{*}\right)$ and $\mathrm{CO}$. Oxygen-containing intermediates oxidize $\mathrm{HC}$ intermediates to produce $\mathrm{CO}$ and subsequently produce $\mathrm{CO}_{2}$ and carbon via the Boudouard reaction (Equation (4)). The atomic carbon formed during the Boudouard reaction first diffuses and dissolves into the metal particles until saturation is reached and then the graphitic carbon starts precipitating to form CNF [27]. For the CC reaction, $\mathrm{HC}$ intermediates self-decompose to produce $\mathrm{H}_{2}$ and carbon [28] and the atomic carbon formed follows the same process of diffusion, saturation, and finally precipitation [29]. 
Transition metal-based catalysts, particularly iron and nickel, are recognized for their ability to decompose carbonaceous gases into filamentous carbon and hydrogen. This capacity for carbon formation is due to the high diffusion rate of carbon in these metals at high temperatures.

The coefficients of diffusion of carbon into transition metals at $550{ }^{\circ} \mathrm{C}$ are $1.2 \times 10^{-7}, 0.8 \times 10^{-7}$, and $0.2 \times 10^{-7} \mathrm{~cm}^{2} / \mathrm{s}$, for $\mathrm{Ni}, \mathrm{Fe}$, and $\mathrm{Co}$, respectively [29]. Consequently, the carbon yield would increase as follows: Ni-based catalyst $>$ Fe-based catalyst $>$ Co-based catalyst. This order, however, was not confirmed by Romero et al. [29], who studied the influence of these active metals ( $\mathrm{Co}, \mathrm{Ni}, \mathrm{Fe})$ and the influence of the zeolite type support on the synthesis of highly graphitized carbon nanofibers produced from the catalytic decomposition of ethylene. They found that the order is rather $\mathrm{Ni}>\mathrm{Co}>$ Fe. They affirmed that this difference is due to the zeolite support that has a different synergistic effect, which explains the important role played by the support, on the activity of the catalyst.

Recently, our research group (GRTP-C \& P) collaborated with Rio Tinto Iron and Titanium (RTIT) for the valorization of a mining residue (upgraded slag oxide (UGSO)) of the upgraded slag (UGS) process to produce titanium slag from ilmenite. Since UGSO is largely composed of iron oxides, in addition to $\mathrm{Mg}$ and $\mathrm{Al}$ oxides, it has been used to produce an effective Ni-functionalized spinel catalyst tested in methane DR, methane mixed reforming [30], and pyrolytic oils SR [31]. In this work, we investigate the efficiency of this new catalyst in ethylene DR and CC reactions to produce $\mathrm{H}_{2}$ and CNF.

\section{Results and Discussion}

\subsection{Fresh Catalyst Characterization}

Table 1 illustrates the BET surface area, average pore volume, and average pore diameter for UGSO and Ni-UGSO with different Ni wt.\%. We can observe that Ni-UGSO has a smaller BET surface area, smaller pore volume, and smaller pore diameter than UGSO; this is due to the formation of other phases (spinels) as shown on the XRD pattern (Figure 1) that cause a rearrangement of UGSO structure (the signification of each symbol in XRD patterns are presented in Table 2). Regarding the effect of $\mathrm{Ni}$ wt.\%, no statistically significant change was found. Generally, Ni addition leads to the reduction of specific surface area, pore volume, and pore size of the catalyst.

Table 1. Textural properties of Ni-UGSO with different Ni contents $(5,10$, and 13 wt.\%).

\begin{tabular}{|c|c|c|c|c|c|}
\hline Catalyst & $\begin{array}{l}\text { BET Surface } \\
\text { Area }\left(\mathrm{m}^{2} \cdot \mathrm{g}^{-1}\right)\end{array}$ & $\begin{array}{c}\text { Average Pore } \\
\text { Volume }\left(\mathrm{cm}^{3} \cdot \mathrm{g}^{-1}\right)^{a}\end{array}$ & $\begin{array}{c}\text { Average Pore } \\
\text { Diameter }(\mathrm{nm})^{b}\end{array}$ & $\begin{array}{c}\text { FWHM } \\
(\mathrm{nm})\end{array}$ & $\begin{array}{l}\text { Ni spinel Crystal } \\
\text { Size }(\mathrm{nm})^{\mathrm{c}}\end{array}$ \\
\hline UGSO & 4.96 & 0.0256 & 20.1 & - & - \\
\hline Ni-UGSO 5\% & 2.91 & 0.0134 & 18.2 & 0.429 & 3.38 \\
\hline Ni-UGSO 10\% & 2.66 & 0.0126 & 19.2 & 0.426 & 3.41 \\
\hline Ni-UGSO 13\% & 2.87 & 0.0132 & 17.7 & 0.429 & 3.38 \\
\hline
\end{tabular}

a Pore volume was obtained from $\mathrm{P} / \mathrm{P}_{0}=0.97 .{ }^{\mathrm{b}}$ Pore diameter was obtained from Barret-Joyner-Halenda (BJH) desorption method. ${ }^{\mathrm{C}} \mathrm{Ni}$ crystallite size was calculated from Scherrer Equation.

Table 2. XRD phase legend.

\begin{tabular}{|c|c|c|c|}
\hline Symbol & Phase & Symbol & Phase \\
\hline$\bullet$ & $\begin{array}{c}\mathrm{MgFeAlO}_{4}, \mathrm{MgFe}_{2} \mathrm{O}_{4} \\
\mathrm{Fe}_{3} \mathrm{O}_{4}, \mathrm{AlFe}_{2} \mathrm{O}_{4}\end{array}$ & $\mathbb{C}$ & $(\mathrm{FeNi}) \mathrm{O}$ \\
\hline $\mathbf{\square}$ & $\mathrm{NiFe}_{2} \mathrm{O}_{4}, \mathrm{FeNiAlO}_{4}$ & 0 & $\mathrm{Fe}$ \\
\hline$\Delta$ & $\mathrm{NiO}$ & $\diamond$ & $\mathrm{Ni}$ \\
\hline 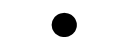 & $\mathrm{MgO}$ & $\Delta$ & $\mathrm{FeNi}_{3}$ \\
\hline$\Delta$ & Carbon & $\hbar$ & $\mathrm{Fe}_{2} \mathrm{O}_{3}$ \\
\hline $\mathfrak{K}$ & $\mathrm{Fe}_{3} \mathrm{C}$ & $\square$ & $\mathrm{FeO}$ \\
\hline
\end{tabular}




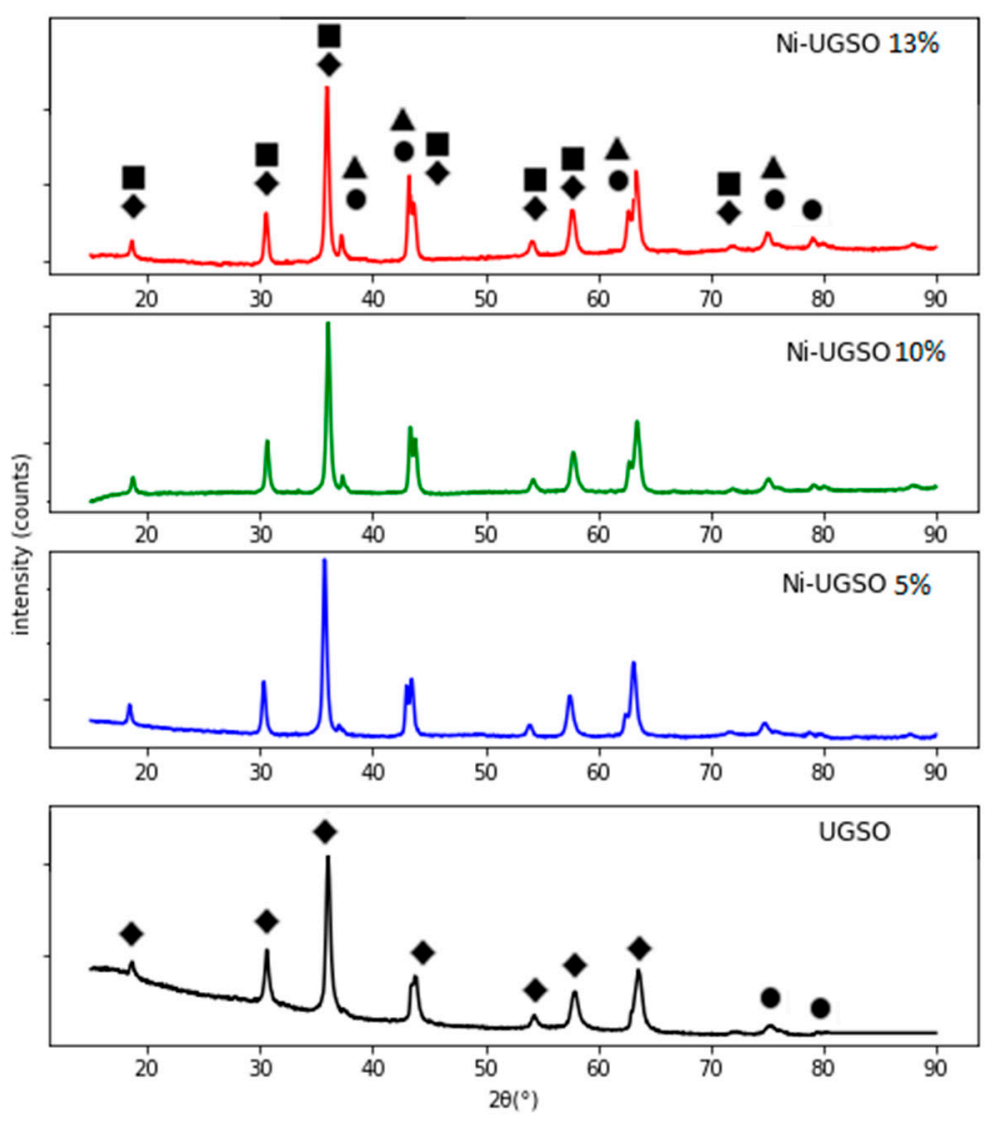

Figure 1. XRD analysis of Ni-UGSO with different Ni contents $(0,5,10$, and 13 wt.\%).

We can also observe that the $\mathrm{NiFe}_{2} \mathrm{O}_{4}$ crystal sizes are nanometric and there is no difference in the crystal size in function of wt.\% of $\mathrm{Ni}$ on the catalyst.

XRD patterns of fresh catalysts with different wt.\% of Ni are shown in Figure 1, which shows that the patterns of the three catalysts are identical. The same family phases have been detected whatever the Ni percentage. In summary, the catalysts are mainly composed of two phases: spinels, in the most probable order of formation (figure of merit (FOM) smallest); $\mathrm{MgFeAlO}_{4}, \mathrm{MgFe}_{2} \mathrm{O}_{4}, \mathrm{Fe}_{3} \mathrm{O}_{4}, \mathrm{NiFeAlO}_{4}$, $\mathrm{AlFe}_{2} \mathrm{O}_{4}, \mathrm{NiFe}_{2} \mathrm{O}_{4}$; and monoxides $(\mathrm{NiO}, \mathrm{MgO})$, which coexist in their solid solution. When comparing to the pattern of fresh UGSO, the new crystalline phases are a clear indication that the Ni has been well integrated into the structure of the UGSO.

According to the TEM images (Figure 2a,c), the catalyst particles are faceted and have a size distribution ranging between $70 \mathrm{~nm}$ and $355 \mathrm{~nm}$.

SAED patterns (Figure 2b,d) indicate that the catalyst is composed of the spinels $\mathrm{NiFe}_{2} \mathrm{O}_{4}$ and $\mathrm{Fe}_{3} \mathrm{O}_{4}$, and oxides $\mathrm{NiO}$ and $(\mathrm{MgFe}) \mathrm{O}$ (Table 3). These results corroborate the XRD analysis results.

Table 3. Indexation of d-spacing measured by SAED.

\begin{tabular}{|c|c|c|}
\hline Measured D-Spacing $\left(\mathrm{A}^{\circ}\right)$ & Indexation & Theoretical D-Spacing $\left(\mathrm{A}^{\circ}\right)$ \\
\hline 1.48 and 1.46 & (4 4 0) $(\mathrm{MgFe}) \mathrm{O} / \mathrm{NiO}$ & 1.47 \\
\hline 1.67 & (4 22 2) $\mathrm{NiFe}_{2} \mathrm{O}_{4} / \mathrm{Fe}_{3} \mathrm{O}_{4}$ & 1.7 \\
\hline 2.03 and 2.06 & $\left(\begin{array}{lll}4 & 0 & 0\end{array}\right)(\mathrm{MgFe}) \mathrm{O} / \mathrm{NiO}$ & 2.08 \\
\hline 2.47 and 2.41 & (3 1 1 1) $\mathrm{NiFe}_{2} \mathrm{O}_{4} / \mathrm{Fe}_{3} \mathrm{O}_{4}$ & 2.51 \\
\hline 2.9 & (2 20$) \mathrm{NiFe}_{2} \mathrm{O}_{4} / \mathrm{Fe}_{3} \mathrm{O}_{4}$ & 2.94 \\
\hline 4.61 & (1 1 1) $\mathrm{NiFe}_{2} \mathrm{O}_{4} / \mathrm{Fe}_{3} \mathrm{O}_{4}$ & 4.8 \\
\hline
\end{tabular}




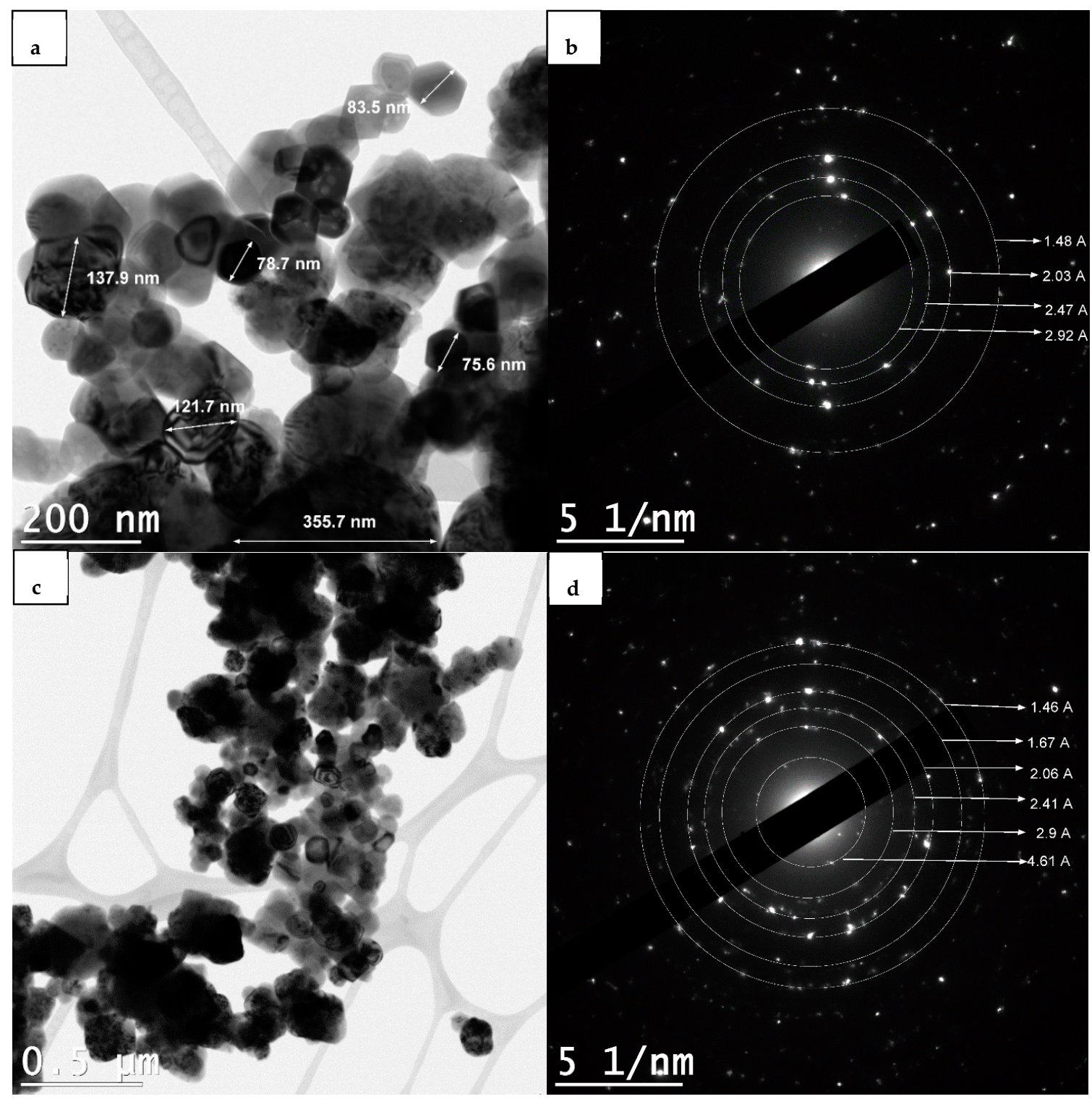

Figure 2. TEM analysis of Ni-UGSO 13\% $(\mathbf{a}, \mathbf{c})$ and its corresponding selected area electron diffraction (SAED) $(\mathbf{b}, \mathbf{d})$.

\subsection{Catalyst Activation and Characterization before DR and CC Reactions}

Before the DR and CC reactions, Ni-UGSO was activated by $\mathrm{H}_{2}$. Concerning structural properties, we notice that the activation has increased the BET surface area, pore volume, and pore diameter (Table 4). The effect of the activation is the reduction of metal oxides into metal particles as we can see in XRD pattern (Figure 3), especially into Ni and Fe metal and their alloys, which leads to a pore enlargement and a BET increase due to the nanometric size of the metallic species proved by TEM (Figure 4).

Table 4. Textural properties of Ni-UGSO 13\% before and after activation.

\begin{tabular}{cccccc}
\hline Catalyst & $\begin{array}{c}\text { BET Surface } \\
\text { Area }\left(\mathbf{m}^{\mathbf{2}} \cdot \mathbf{g}^{-\mathbf{1}}\right)\end{array}$ & $\begin{array}{c}\text { Average Pore } \\
\text { Volume }\left(\mathbf{c m}^{\mathbf{3}} \cdot \mathbf{g}^{-\mathbf{1}}\right)^{\mathbf{a}}\end{array}$ & $\begin{array}{c}\text { Average Pore } \\
\text { Diameter }(\mathbf{n m})^{\mathbf{b}}\end{array}$ & FWMH & $\begin{array}{c}\text { Ni Crystallite } \\
\text { Size }(\mathbf{n m})^{\mathbf{c}}\end{array}$ \\
\hline Fresh Ni-UGSO 13\% & 2.87 & 0.0132 & 17.7 & 0.43 & 3.4 \\
\hline Activated Ni-UGSO 13\% & 4.81 & 0.0238 & 19.1 & 1.39 & 1.2 \\
\hline
\end{tabular}

${ }^{a}$ Pore volume was obtained from $\mathrm{P} / \mathrm{P}_{0}=0.97 .{ }^{\mathrm{b}}$ Pore diameter was obtained from Barret-Joyner-Halenda (BJH) desorption method. ${ }^{\mathrm{c}} \mathrm{Ni}$ crystallite size was calculated from Scherrer Equation. 
Comparison between fresh and activated Ni-UGSO 13\% catalyst

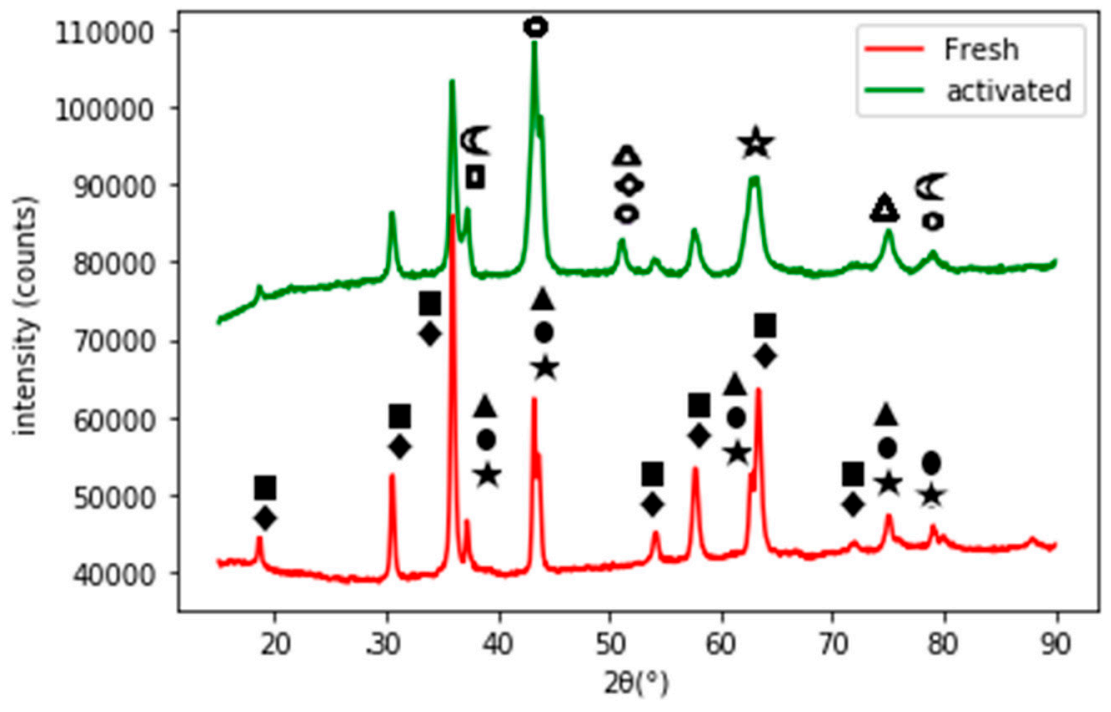

Figure 3. XRD analysis of Ni-UGSO 13\% before and after activation.
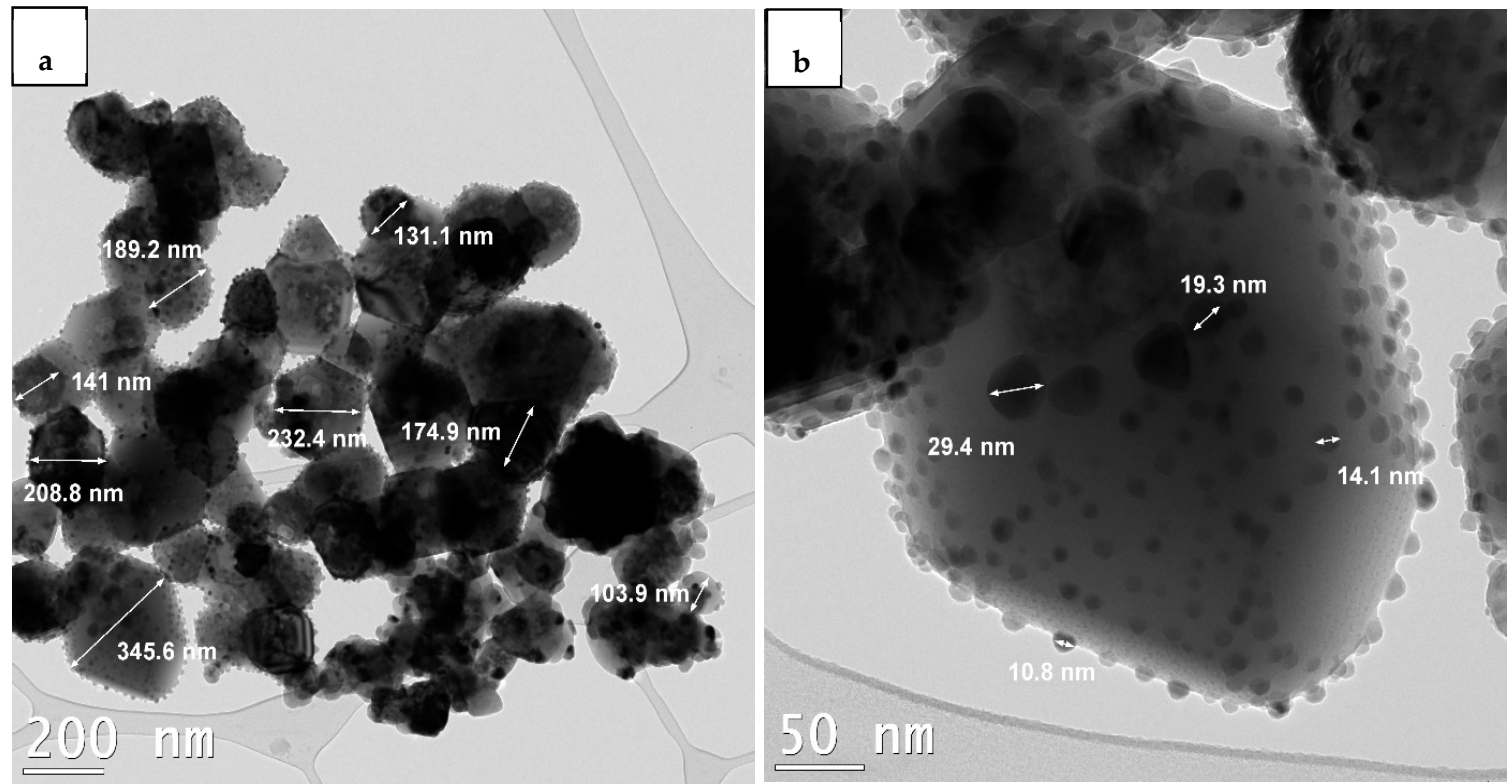

Figure 4. TEM analysis of activated Ni-UGSO 13\%, (a) support particle size and (b) crystallite size.

When comparing the XRD patterns of the catalyst structure before and after activation by $\mathrm{H}_{2}$, we can observe the appearance of peaks attributed to the metallic phases $\mathrm{Ni}, \mathrm{Fe}$, and their alloys. Yu et al. [32] have shown that the reduction of catalysts containing Ni and Fe leads to the formation of their alloys such as tarnite and kamacite, and the proportion of Ni:Fe on the alloy after reduction depends on their initial mass ratio. We can also observe the presence of $\mathrm{FeO}$, which means that the magnetite has been reduced partially into wüstite and iron.

TPR analysis was used to determine the reduction temperatures of the different metal species present in the catalyst. The TPR profiles for the three different catalysts with different wt.\% (Figure 5) have the same shape with three distinctive peaks. The difference is in the amount of $\mathrm{H}_{2}$ consumed, which, as expected, increases with the wt.\% of $\mathrm{Ni}$ in the catalyst. 

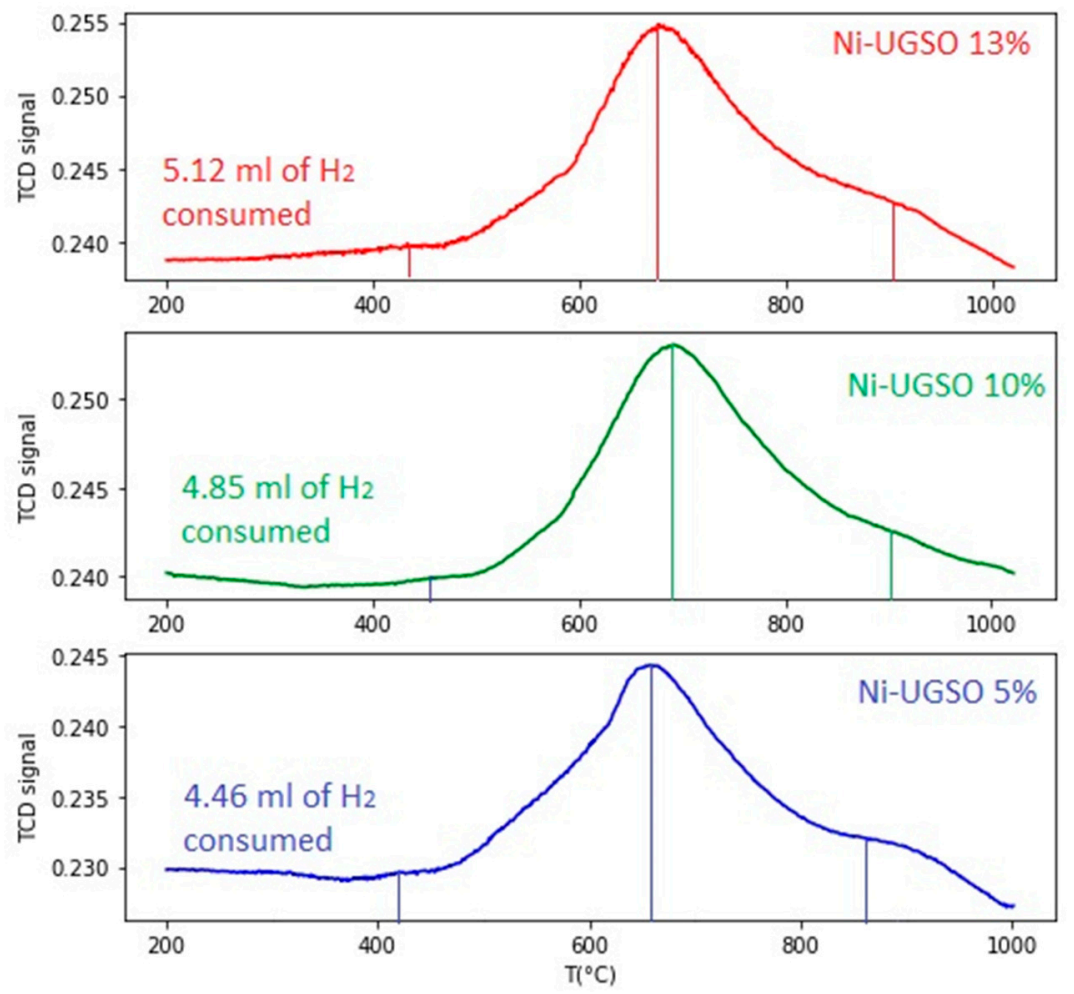

Figure 5. TPR analysis for Ni-UGSO with different Ni contents $(5,10$, and 13 wt.\%).

In fact, the reduction temperature of metals depends on their interaction with the support and their location, as well as the structure to which it belongs (oxide or spinel). The reduction of Ni-UGSO by $\mathrm{H}_{2}$ essentially leads to the formation of metallic $\mathrm{Fe}$ and Ni particles in addition to their solid solution. $\mathrm{Al}$ and $\mathrm{Mg}$ are resistant to reduction and remain in their oxidized state.

The analysis of the Ni-UGSO 13\% TPR pattern depicts the main reduction peak (the one in the middle) and two others. The first peak can be attributed to the reduction of free $\mathrm{NiO}$ (not in interaction with all other phases) and the reduction of $\mathrm{Fe}^{3+}$ to $\mathrm{Fe}^{2+}$. The second peak can be assigned to the reduction of both $\mathrm{Fe}^{3+}$ species to $\mathrm{Fe}^{2+}$ and $\mathrm{Fe}$, and $\mathrm{Ni}^{2+}$ to $\mathrm{Ni}(\mathrm{NiO}$ moderately interacting with other phases). The third peak can be attributed to the reduction of $\mathrm{NiO}$ strongly interacting with $\mathrm{MgO}$ or having a strong interaction with spinel $\mathrm{MgFeAlO}_{4}$ [30].

As shown in Figure 4, the reduction of the catalyst by $\mathrm{H}_{2}$ led to the formation of metal crystallites with different sizes on the surface of crystals that have not been reduced ( $\mathrm{Al}$ and $\mathrm{Mg}$ oxides). Similar results were found by Romero et al. [29], who studied the reduction of zeolite-supported $\mathrm{Ni}$ - and Fe-based catalysts. They observed Fe and Ni crystallites with different distributions formed on the surface of the zeolite. In fact, the activation of catalysts by $\mathrm{H}_{2}$ led to the reduction of oxides into small metallic particles, which are the active phase for the growth of CNF.

As depicted in Figure $4 \mathrm{~b}$, the crystallite sizes are in the range of 10-30 nm. Yu et al. [32] have found that the reduction of the Ni:Fe (6:1) catalyst has an average crystallite size of $6 \mathrm{~nm}$ with a Gaussian-like distribution. The difference observed when comparing our results with those in the literature might be due to a different $\mathrm{Ni}$ :Fe ratio and/or to the reduction conditions (nature of the substrate and rate of heat and mass transfer). Some sintering seems to have taken place due to reduction because, if we compare Figures 4a and 2, we notice that the support particle size has increased (100-400 nm).

The EDX pattern (Figure 6) shows that these crystallites are composed mainly of Ni and Fe and no $\mathrm{O}$ has been detected. This proves that these crystallites are metallic and they are $\mathrm{Ni}, \mathrm{Fe}$, and/or $\mathrm{Ni}-\mathrm{Fe}$ alloys, thus corroborating the already presented XRD results. 


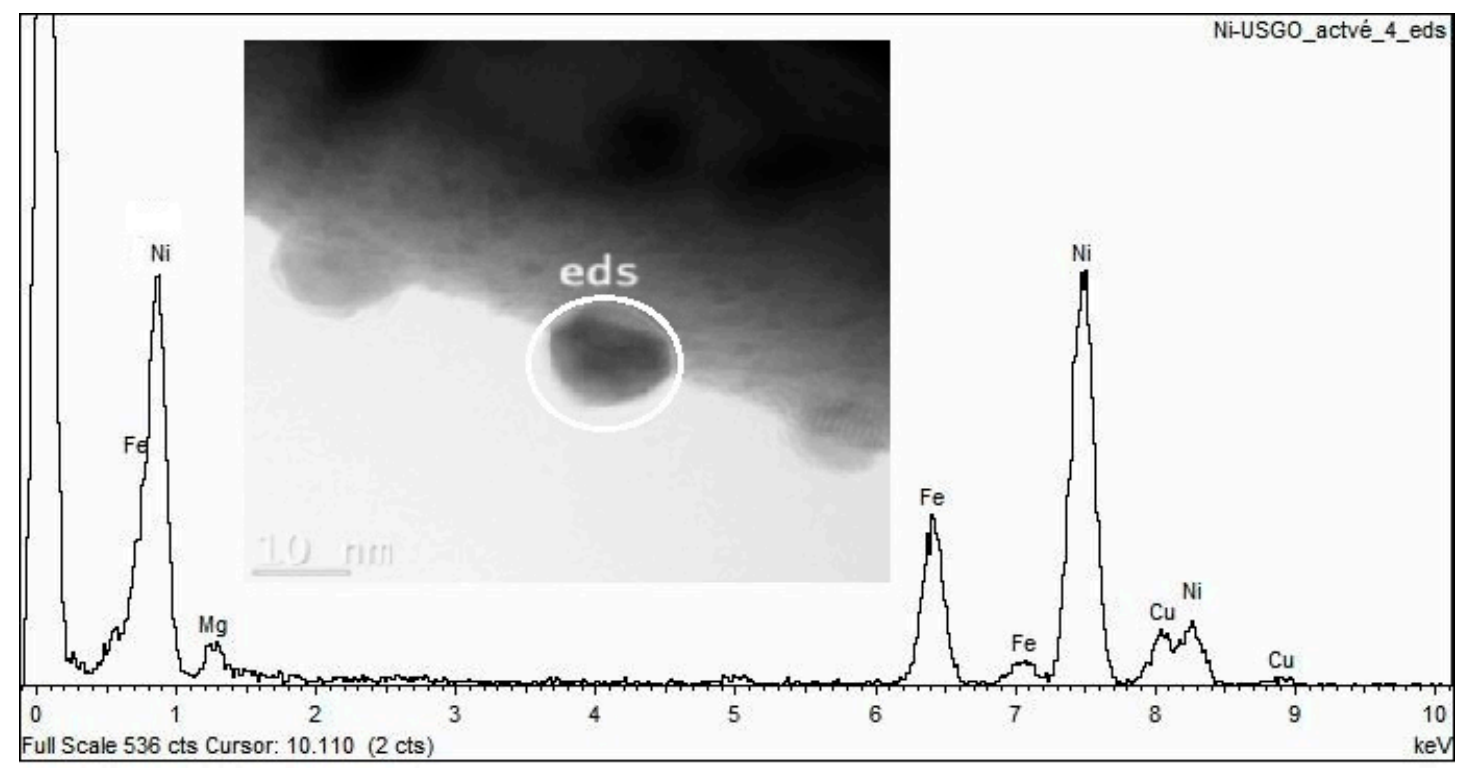

Figure 6. EDX analysis of activated Ni-UGSO 13\%.

\subsection{Ni-UGSO Catalyst Performance}

\subsubsection{Thermodynamic Investigation}

FactSage software was used to study the thermodynamic equilibrium of the $\mathrm{C}_{2} \mathrm{H}_{4} \mathrm{CC}$ and DR reactions at different conditions of temperature $\left(450-850{ }^{\circ} \mathrm{C}\right)$ and molar ratios $\mathrm{C}_{2} \mathrm{H}_{4} / \mathrm{CO}_{2}(1 / 1-3 / 1)$ at atmospheric pressure. Equilibrium composition, heat, and enthalpy of the reaction, as well as the amount of deposited carbon, were studied during this research. This investigation allowed us to choose the experimental conditions. The results are shown in Figures 7-9.
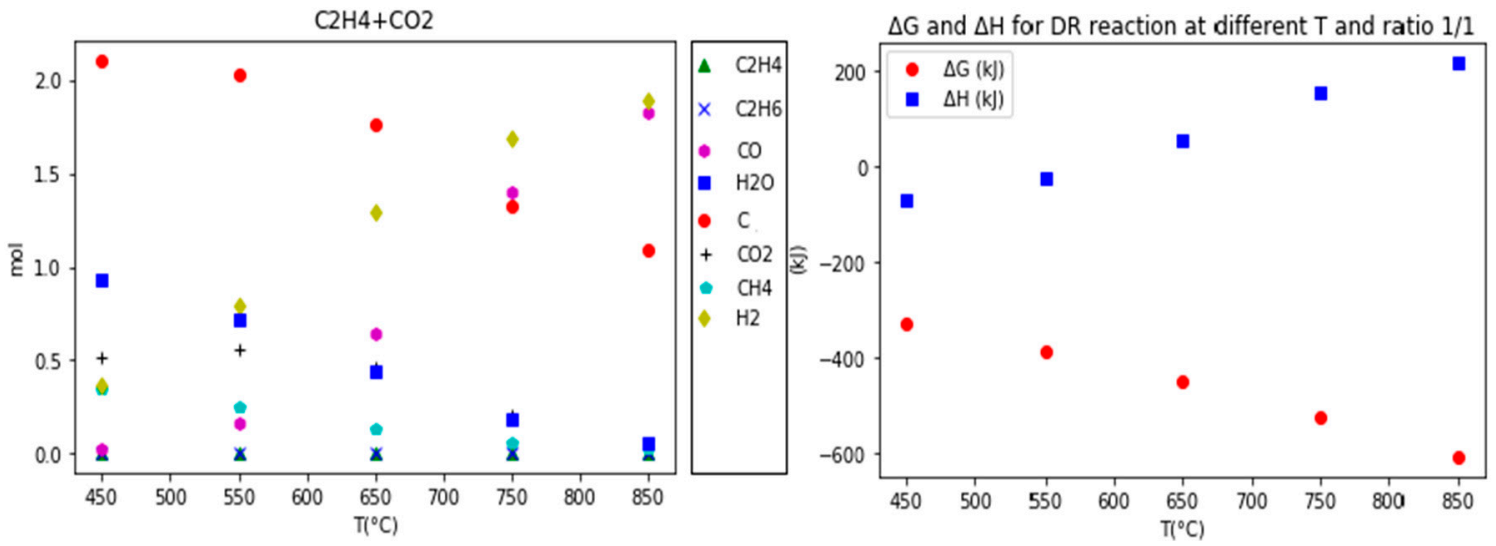

Figure 7. Thermodynamic study of DR reaction at different temperature at ratio 1/1.

$\Delta \mathrm{H}$ is negative for the $\mathrm{CC}$ reaction, which means that the reaction is exothermic, and it increases with the increase of temperature (Figure 9). The $\Delta \mathrm{H}$ of the DR reaction is negative for temperatures below $600{ }^{\circ} \mathrm{C}$ for both ratios. This means that at temperatures higher than $600{ }^{\circ} \mathrm{C}$ the reaction is endothermic. The heat of this reaction increases with the increase of the amount of ethylene in the feedstock.

The decline of $\Delta \mathrm{G}$ with temperature illustrates that the equilibrium is displaced toward the products. For the $\mathrm{CC}$ reaction, at temperatures below $700{ }^{\circ} \mathrm{C}, \Delta \mathrm{G}$ is positive and, therefore, the reaction is not taking place. For the DR reaction, $\Delta \mathrm{G}$ is higher at higher $\mathrm{C}_{2} \mathrm{H}_{4} / \mathrm{CO}_{2}$ ratios, which means that conversion is favored. 

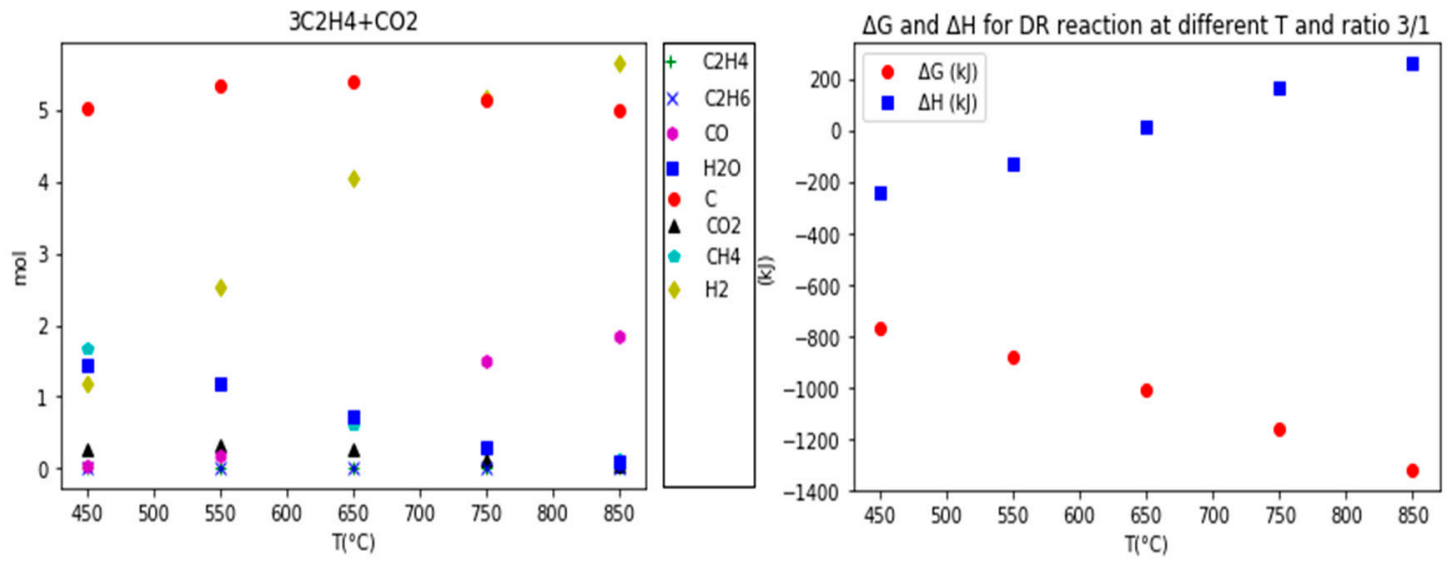

Figure 8. Thermodynamic study of DR reaction at different temperature at ratio 3/1.
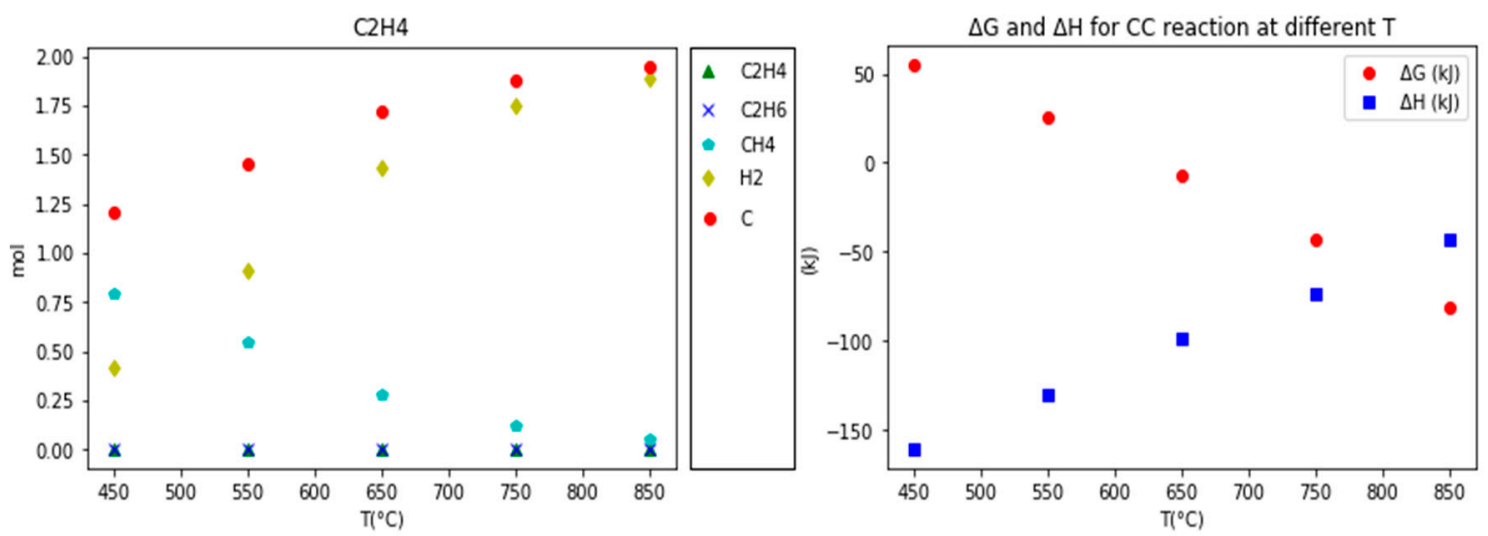

Figure 9. Thermodynamic study of CC reaction at different temperature.

For the $\mathrm{CC}$ reaction, $\mathrm{H}_{2}$ and carbon amounts at the equilibrium increase with temperature (Figure 9). However, for the DR reaction, the $\mathrm{H}_{2}$ amount increases with the temperature for both ratios, while the $\mathrm{C}$ amount decreases with the temperature at ratio $1 / 1$ and reaches its maximum at $650{ }^{\circ} \mathrm{C}$ at a ratio of $3 / 1$.

Based on these results, the three following temperatures have been chosen to be studied experimentally: $550{ }^{\circ} \mathrm{C}, 650{ }^{\circ} \mathrm{C}$, and $750{ }^{\circ} \mathrm{C}$. Since we want to maximize carbon and $\mathrm{H}_{2}$ production, a $3 / 1$ ratio of $\mathrm{C}_{2} \mathrm{H}_{4} / \mathrm{CO}_{2}$ was chosen.

\subsubsection{Study of CC Reaction}

The effect of temperature and Ni percentage on $\mathrm{CNF}$ and $\mathrm{H}_{2}$ yields, as well as carbon growth rate, are presented in Figure 10 and Table 5, respectively.

Table 5. Carbon growth rate for the CC reaction using Ni-UGSO with different $\mathrm{Ni}$ wt.\% (5, 10, and 13) at $\mathrm{T}=550{ }^{\circ} \mathrm{C}, 650{ }^{\circ} \mathrm{C}$, and $750{ }^{\circ} \mathrm{C}$ for $2 \mathrm{~h}$ TOS.

\begin{tabular}{cccc}
\hline \multirow{2}{*}{ Catalyst } & \multicolumn{3}{c}{ Carbon Growth Rate $\left(\mathbf{g}_{\mathbf{C}} \cdot \mathbf{g}_{\mathbf{c a t}}{ }^{-\mathbf{1}} \cdot \mathbf{h}^{\mathbf{- 1}}\right) \mathbf{A t}$} \\
\cline { 2 - 4 } & $\mathbf{5 5 0}{ }^{\circ} \mathbf{C}$ & $\mathbf{6 5 0}^{\circ} \mathbf{C}$ & $\mathbf{7 5 0}^{\circ} \mathbf{C}$ \\
\hline Ni-UGSO 5\% & 1.42 & 1.7 & 1.78 \\
Ni-UGSO 10\% & 1.78 & 1.82 & 1.94 \\
Ni-UGSO 13\% & 2.1 & 2.2 & 2.8 \\
\hline
\end{tabular}

Yu et al. [32], who used a bimetallic catalyst of Ni-Fe with different $\mathrm{Ni}$ loading levels, found that productivity is higher for higher $\mathrm{T}$ and higher Ni loading. This work shows that $\mathrm{C}$ and $\mathrm{H}_{2}$ yields 
increase with temperature (Figure 10). This is in accordance with the previously reported literature [32]. Moreover, the carbon growth rate increases with $\mathrm{T}$ because the solubility and diffusion of the carbon in the solid metallic phases also increases with $\mathrm{T}$ [33]. This effect is even more pronounced at higher percentages of $\mathrm{Ni}$ in the catalyst.
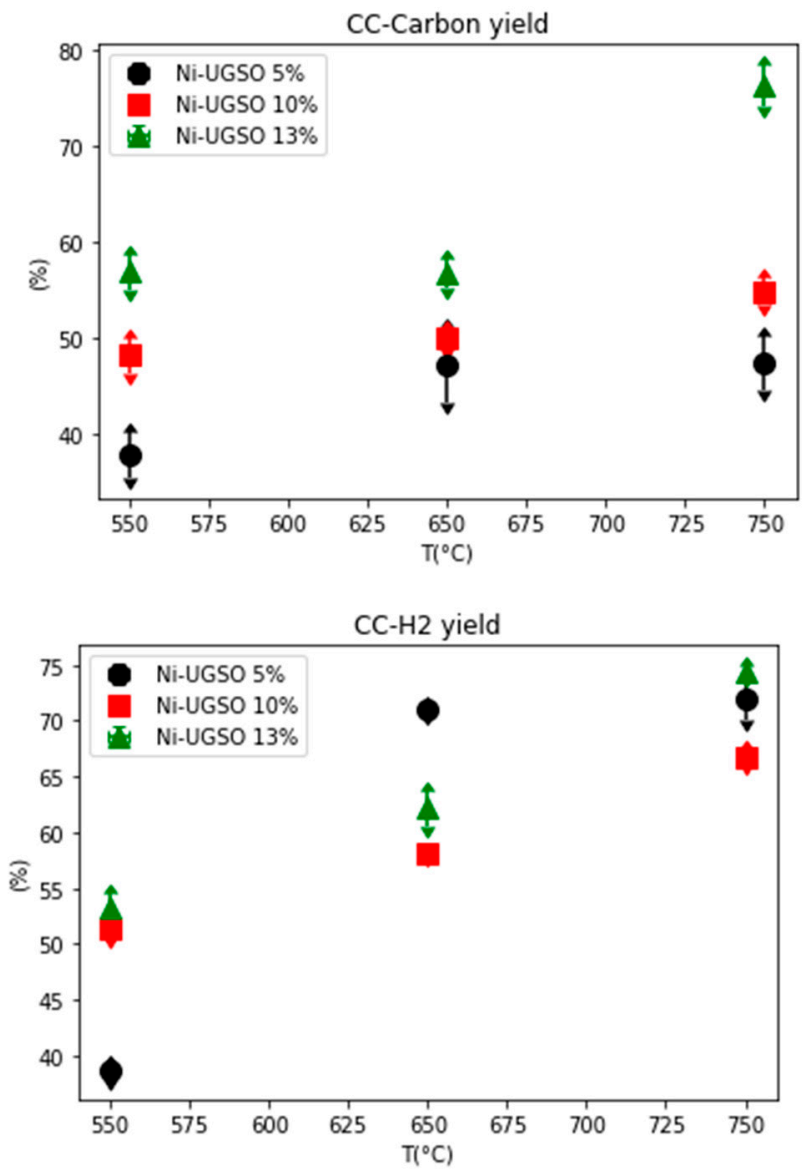

Figure 10. Carbon and $\mathrm{H}_{2}$ yields for the CC reaction using Ni-UGSO with different Ni wt.\% (5, 10, and 13) at $\mathrm{T}=550{ }^{\circ} \mathrm{C}, 650^{\circ} \mathrm{C}$, and $750{ }^{\circ} \mathrm{C}$ for $2 \mathrm{~h}$ time-on-stream (TOS).

Since the highest carbon and $\mathrm{H}_{2}$ yields were observed at $\mathrm{T}=650{ }^{\circ} \mathrm{C}$ and $w \mathrm{wt} . \%$ of $\mathrm{Ni}=13 \%$, the reaction results at these conditions are presented in detail in Table 6 and Figure 11.

Table 6. General experimental results for CC reaction using Ni-UGSO $13 \%$ at $750{ }^{\circ} \mathrm{C}$ for $2 \mathrm{~h}$ TOS.

\begin{tabular}{ll}
\hline $\mathrm{C}_{2} \mathrm{H}_{4}(\mathrm{~mL} / \mathrm{min})$ & 30 \\
$\mathrm{Ar}(\mathrm{mL} / \mathrm{min})$ & 10 \\
Catalyst weight $(\mathrm{g})$ & 0.5 \\
$\mathrm{TOS}(\mathrm{min})$ & 120 \\
$\mathrm{GHSV}_{\mathrm{STP}}\left(\mathrm{mL} \cdot \mathrm{h}^{-1} \cdot \mathrm{g}\right)$ & 4800 \\
$\mathrm{C}_{2} \mathrm{H}_{4} / \mathrm{Ar}$ & 3 \\
$\mathrm{Ar} / \mathrm{C}_{2} \mathrm{H}_{4}$ & 0.33 \\
Carbon $(\mathrm{g})$ & 2.8 \\
Carbon production rate $\left(\mathrm{g}_{\mathrm{C}} \cdot \mathrm{g}_{\mathrm{cat}}{ }^{-1} \cdot \mathrm{min}^{-1}\right)$ & 0.047 \\
Carbon production rate $\left(\mathrm{g}_{\mathrm{C}} \cdot \mathrm{g}_{\mathrm{cat}}{ }^{-1} \cdot \mathrm{h}^{-1}\right)$ & 2.8 \\
Carbon yield $(\%)$ & 76.25 \\
Total $\mathrm{H}_{2}$ yield $(\%)$ & 74.46 \\
Total $\mathrm{C}_{2} \mathrm{H}_{4}$ conversion $(\%)$ & 92.24 \\
Mass balance error for $\mathrm{C}(\%)$ & 3.31 \\
Mass balance error for $\mathrm{H}(\%)$ & 0.08 \\
\hline
\end{tabular}



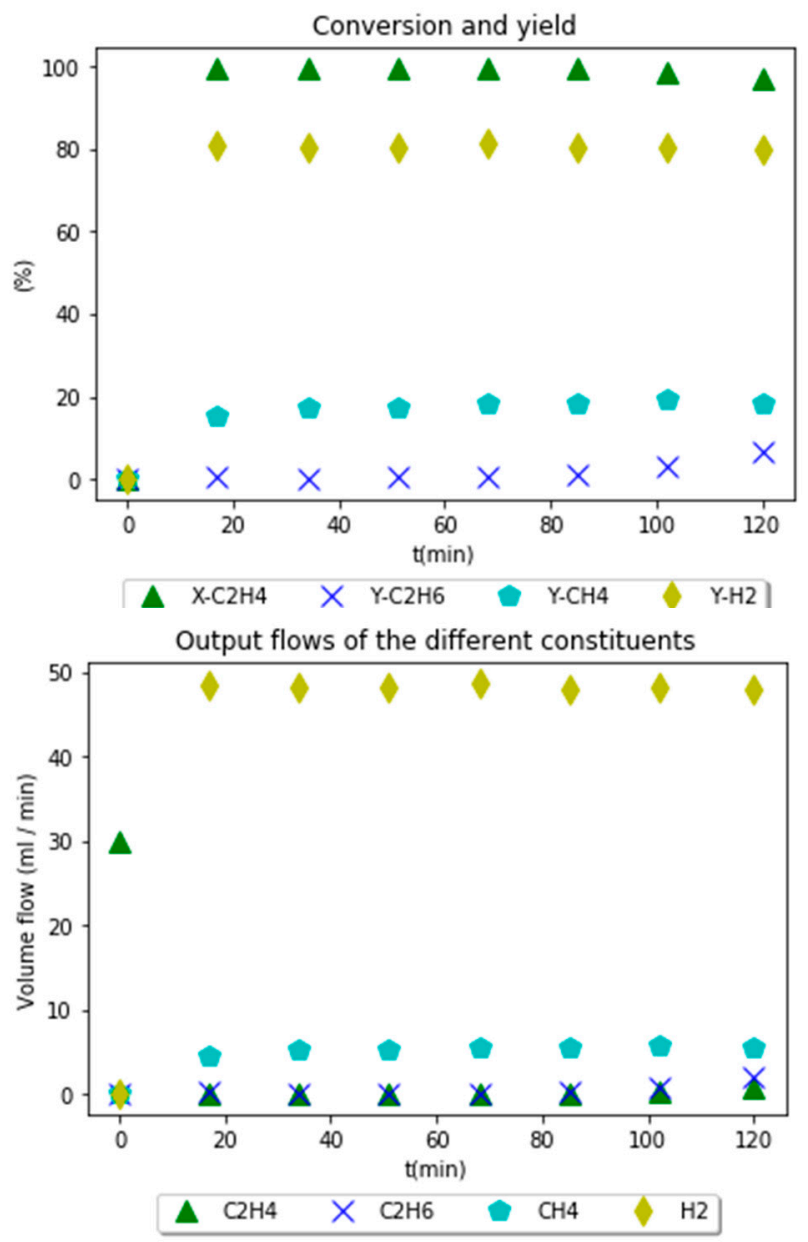

Figure 11. Experimental results for CC reaction using Ni-UGSO $13 \%$ at $750{ }^{\circ} \mathrm{C}$.

Overall, the highest carbon and $\mathrm{H}_{2}$ yields, $\mathrm{Y}_{\mathrm{H} 2}=74.46 \%$ and $\mathrm{Y}_{\mathrm{C}}=76.25 \%$, respectively, are observed at $\mathrm{T}=750{ }^{\circ} \mathrm{C}$ and $13 \%$ of Ni. Thus, the carbon turnover frequency (TOF) expressed per mass of catalysts was $2.8 \mathrm{~g}_{\mathrm{C}} \cdot \mathrm{g}_{\mathrm{cat}}{ }^{-1} \cdot \mathrm{h}^{-1}$ at a flow rate of $30 \mathrm{~mL} / \mathrm{min}$ (Table 6). When compared to the catalysts used in the literature, this catalyst has shown similar to better performance. Yu et al. [32] have produced $3 \mathrm{~g}_{\mathrm{C}} \cdot \mathrm{g}_{\mathrm{cat}}{ }^{-1} \cdot \mathrm{h}^{-1}$ and $2.55 \mathrm{~g}_{\mathrm{C}} \cdot \mathrm{g}_{\mathrm{cat}}{ }^{-1} \cdot \mathrm{h}^{-1}$ using bimetallic catalysts $\mathrm{Ni}-\mathrm{Fe}(6-1)$ and $\mathrm{Ni}-\mathrm{Fe}(5-5)$, respectively, with a feed of $\mathrm{C}_{2} \mathrm{H}_{4} / \mathrm{CO} / \mathrm{H}_{2}(30 / 10 / 10)$. Diaz et al. [34] studied $\mathrm{Ni}-\mathrm{SiO}_{2}$ catalyst for the catalytic decomposition of ethylene to produce carbon, between $600{ }^{\circ} \mathrm{C}$ and $700{ }^{\circ} \mathrm{C}$. They obtained the maximum of carbon at $600{ }^{\circ} \mathrm{C}$ with $2 \mathrm{~g}_{\mathrm{C}} \cdot \mathrm{g}_{\mathrm{cat}}{ }^{-1} \cdot \mathrm{h}^{-1}$ for $60 \mathrm{~mL} / \mathrm{min}$ of $\mathrm{C}_{2} \mathrm{H}_{4}$.

Figure 11 shows that the steady-state has been reached very fast during the first 20 min of TOS. The conversion of $\mathrm{C}_{2} \mathrm{H}_{4}$ is nearly $100 \%$ and starts slightly decreasing in the last $20 \mathrm{~min}$. The hydrogen yield is also constant around $80 \%$ for 120 min while the rate of carbon formation is also high and equal to $2.82 \mathrm{gC}_{\mathrm{C}} \mathrm{g}_{\mathrm{ca}}{ }^{-1} \cdot \mathrm{h}^{-1}$. The observed high and constant rates of carbon and $\mathrm{H}_{2}$ formation are due to the high activity of the catalyst at the beginning of the reaction; moreover, even though carbon was formed, the catalyst did not show any deactivation during the TOS of operation. The latter can be explained by the type of carbon formed. Indeed, the carbon formed was analyzed by SEM and it has been proven that it was under the form of CNF (Figure 12), which was not affecting considerably the access of the reactants at the surface of the catalyst. 


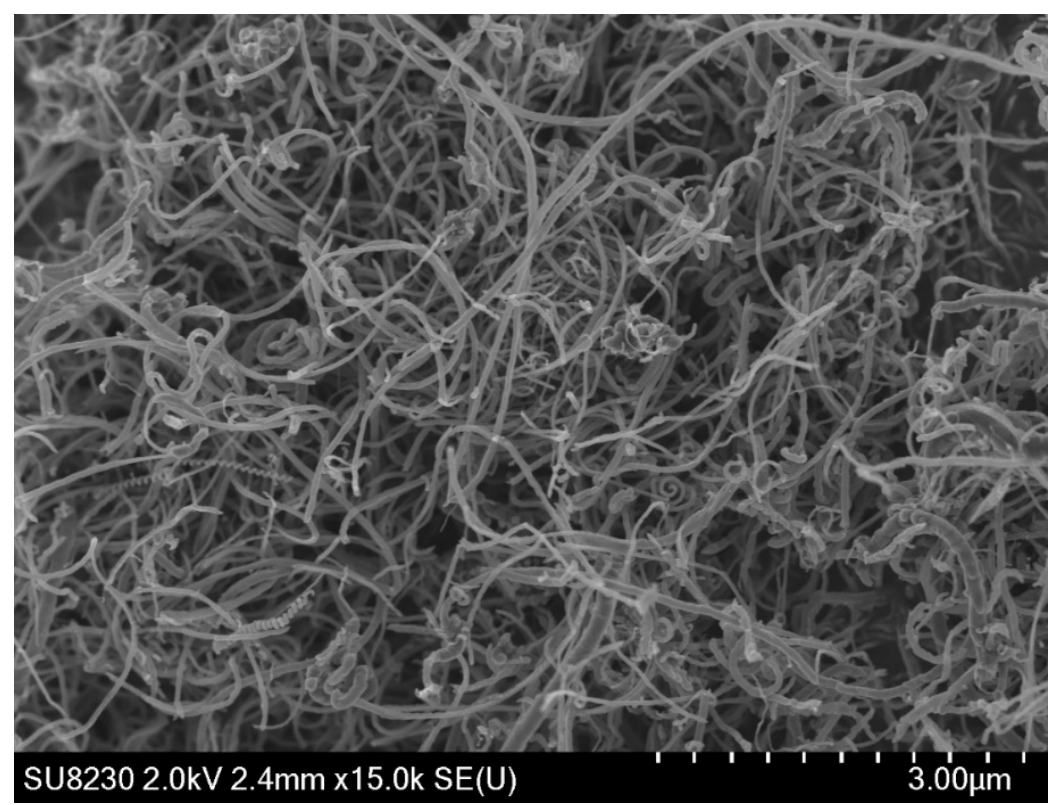

Figure 12. SEM analysis of CNF produced at $750{ }^{\circ} \mathrm{C}$ using Ni-UGSO $13 \%$ for CC reaction.

\subsubsection{Study of DR Reaction}

The effect of temperature and Ni percentage on CNF and $\mathrm{H}_{2}$ yields, as well as carbon growth rate, are illustrated in Figure 13 and Table 7, respectively.
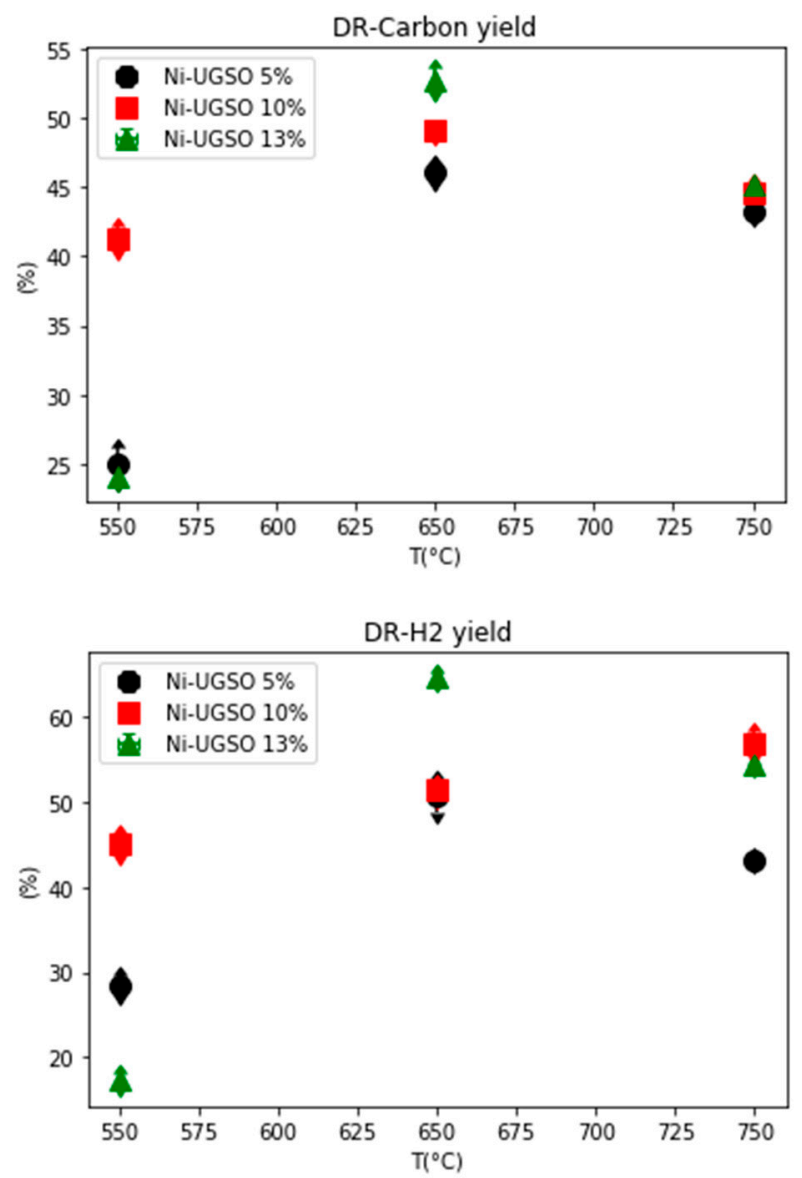

Figure 13. Carbon and $\mathrm{H}_{2}$ yield for the DR reaction using Ni-UGSO with different $\mathrm{Ni} w \mathrm{wt} \%(5,10$, and 13) at $\mathrm{T}=550{ }^{\circ} \mathrm{C}, 650{ }^{\circ} \mathrm{C}$, and $750{ }^{\circ} \mathrm{C}$ for $2 \mathrm{~h}$ TOS. 
Table 7. Carbon growth rate for the DR reaction using Ni-UGSO with different $\mathrm{Ni} w \mathrm{wt} \%$ (5, 10, and 13) at $\mathrm{T}=550{ }^{\circ} \mathrm{C}, 650^{\circ} \mathrm{C}$, and $750{ }^{\circ} \mathrm{C}$ for $2 \mathrm{~h}$ TOS.

\begin{tabular}{cccc}
\hline \multirow{2}{*}{ Catalyst } & \multicolumn{3}{c}{ Carbon Growth Rate $\left(\mathrm{g}_{\mathrm{C}} \cdot \mathbf{g}_{\mathbf{c a t}}{ }^{-\mathbf{1}} \cdot \mathbf{h}^{\mathbf{- 1}}\right) \mathbf{A t}$} \\
\cline { 2 - 4 } & $\mathbf{5 5 0}{ }^{\circ} \mathbf{C}$ & $\mathbf{6 5 0}{ }^{\circ} \mathbf{C}$ & $\mathbf{7 5 0}{ }^{\circ} \mathbf{C}$ \\
\hline Ni-UGSO 5\% & 1.1 & 1.96 & 1.83 \\
Ni-UGSO 10\% & 1.7 & 2.05 & 1.9 \\
Ni-UGSO 13\% & 0.9 & 2.25 & 1.96 \\
\hline
\end{tabular}

Figure 13 shows that the carbon yield for all Ni contents has a maximum at $650{ }^{\circ} \mathrm{C}$. Although it seems that the same applies to the $\mathrm{H}_{2}$ yield, the latter keeps increasing in the case of the $10 \% \mathrm{Ni}$ content catalyst. The amount of $\mathrm{Ni}$ active sites is a parameter that plays a significant role in terms of catalytic activity. The BET results in Table 1 show that the specific surface and the average pore volume is not a function of the Ni content in the range between 5 and $13 \mathrm{wt} . \%$. The small difference observed in the case of $10 \mathrm{wt} . \% \mathrm{Ni}$ catalyst is within the experimental error and cannot be used as a differentiation argument. In light of the above, the difference in $\mathrm{H}_{2}$ yield observed in the case of the 10 wt.\% Ni catalysts might be explained in the following way:

(a) As expected by thermodynamic calculations, the temperature around $600^{\circ} \mathrm{C}$ is optimal for carbon production and this is clearly shown by the experiments in Figure 13;

(b) At higher temperatures (i.e., $750{ }^{\circ} \mathrm{C}$ ), carbon production decreases, but the $\mathrm{H}_{2}$ yield must increase. Although this is the trend observed with the $10 \mathrm{wt} . \% \mathrm{Ni}$ catalyst, in the case of $5 \mathrm{wt} . \% \mathrm{Ni}$, this increase is nil. In the case of $13 \mathrm{wt} . \% \mathrm{Ni}$, we observe the opposite. The most plausible speculation is that, at $5 \mathrm{wt} . \% \mathrm{Ni}$, the active catalytic sites are low, while, at $13 \mathrm{wt} . \% \mathrm{Ni}$, the Ni distribution is less than optimal. It is well known that in almost all heterogeneous catalysts there is an optimal active metal content below which and above which the catalytic activity decreases.

Since the target of the manuscript is the comparison of two regimes with a number of Ni-UGSO formulations, there are no available surface data to support further discussion. Our continuous efforts are now focusing namely on these aspects.

Both carbon and hydrogen yields are maximal at $650{ }^{\circ} \mathrm{C}$. This behavior can be explained by carbon and $\mathrm{H}_{2}$ formation and consumption reactions. In fact, carbon is produced from $\mathrm{C}_{2} \mathrm{H}_{4}$ decomposition and Boudouard reaction and consumed by the gasification reaction, while $\mathrm{H}_{2}$ is produced by $\mathrm{C}_{2} \mathrm{H}_{4}$ decomposition and consumed by RWGS reaction. $\mathrm{C}_{2} \mathrm{H}_{4}$ decomposition and RWGS reactions are favored by high temperatures. Boudouard has a thermodynamic maximum of carbon formation around $550^{\circ} \mathrm{C}$. At $\mathrm{T}$ lower than $650^{\circ} \mathrm{C}$, the formation rate exceeds the consumption rate

Concerning the effects of $\mathrm{Ni}$, the yield of carbon and $\mathrm{H}_{2}$ increases with the increase of the $\mathrm{Ni}$ weight percentage in the catalyst, and this is attributed to the higher catalytic activity at higher $\mathrm{Ni}$ loading levels and consequently faster reaction rates. We can notice an exception for Ni-UGSO $13 \%$ at $\mathrm{T}=550{ }^{\circ} \mathrm{C}$ where the yields are very low. This could be explained by the fact that the catalyst at such a low $\mathrm{T}$ with such a high load of $\mathrm{Ni}$ has not reached its highest activity within $2 \mathrm{~h}$.

Since the highest carbon and $\mathrm{H}_{2}$ yields were observed at $\mathrm{T}=650{ }^{\circ} \mathrm{C}$ and $\mathrm{wt} . \%$ of $\mathrm{Ni}=13 \%$, the reaction results at these conditions are presented in detail in Table 8 and Figure 14.

Ni-based catalysts have been used in the past for DR reactions, especially for methane and ethanol, but there are few studies on ethylene dry reforming. Jankhah et al. [15] examined in detail the dry reforming reaction of ethanol using activated stainless-steel strips as a catalyst (strip surface of $0.04 \mathrm{~m}^{2}$ ). Experiments have shown that the results that give the best yields of carbon and $\mathrm{H}_{2}$ are obtained at a temperature of $550{ }^{\circ} \mathrm{C}$. They have obtained a carbon rate equal to $3.6 \mathrm{~g} \cdot \mathrm{h}^{-1}$ and an $\mathrm{H}_{2}$ yield of $76.33 \%$. Since this catalyst is $2 \mathrm{D}$ and not $3 \mathrm{D}$, the equivalent carbon TOF is related to the catalyst surface and not to the weight and is equal to $90 \mathrm{~g} \cdot \mathrm{h}^{-1} \cdot \mathrm{m}^{-2}$. 
Table 8. General experimental results for the DR reaction at $650{ }^{\circ} \mathrm{C}$ and Ni-UGSO $13 \%$ for $2 \mathrm{~h}$ TOS.

\begin{tabular}{ll}
\hline $\mathrm{C}_{2} \mathrm{H}_{4}(\mathrm{~mL} / \mathrm{min})$ & 30 \\
$\mathrm{CO}_{2}(\mathrm{~mL} / \mathrm{min})$ & 10 \\
Catalyst weight $(\mathrm{g})$ & 0.5 \\
$\mathrm{TOS}(\mathrm{min})$ & 120 \\
$\mathrm{GHSV}_{\mathrm{STP}}\left(\mathrm{mL} \cdot \mathrm{h}^{-1} \cdot \mathrm{g}^{-1}\right)$ & 4800 \\
$\mathrm{C}_{2} \mathrm{H}_{4} / \mathrm{CO}_{2}$ & 3 \\
$\mathrm{CO}_{2} / \mathrm{C}_{2} \mathrm{H}_{4}$ & 0.33 \\
Carbon $(\mathrm{g})$ & 2.25 \\
Carbon production rate $\left(\mathrm{g}_{\mathrm{C}} \cdot \mathrm{g}_{\mathrm{cat}}{ }^{-1} \cdot \mathrm{min}^{-1}\right)$ & 0.0375 \\
Carbon production rate $\left(\mathrm{g}_{\mathrm{C}} \cdot \mathrm{g}_{\mathrm{cat}}{ }^{-1} \cdot \mathrm{h}^{-1}\right)$ & 2.25 \\
Carbon yield $(\%)$ & 53.57 \\
Total $\mathrm{H}_{2}$ yield $(\%)$ & 67.47 \\
Total $\mathrm{C}_{2} \mathrm{H}$ & conversion $(\%)$ \\
Total CO & 91.29 \\
Mass balance error for $\mathrm{C}(\%)$ & 88.48 \\
Mass balance error for $\mathrm{H}(\%)$ & 9.16 \\
Mass balance error for $\mathrm{O}(\%)$ & 1.46 \\
\hline
\end{tabular}
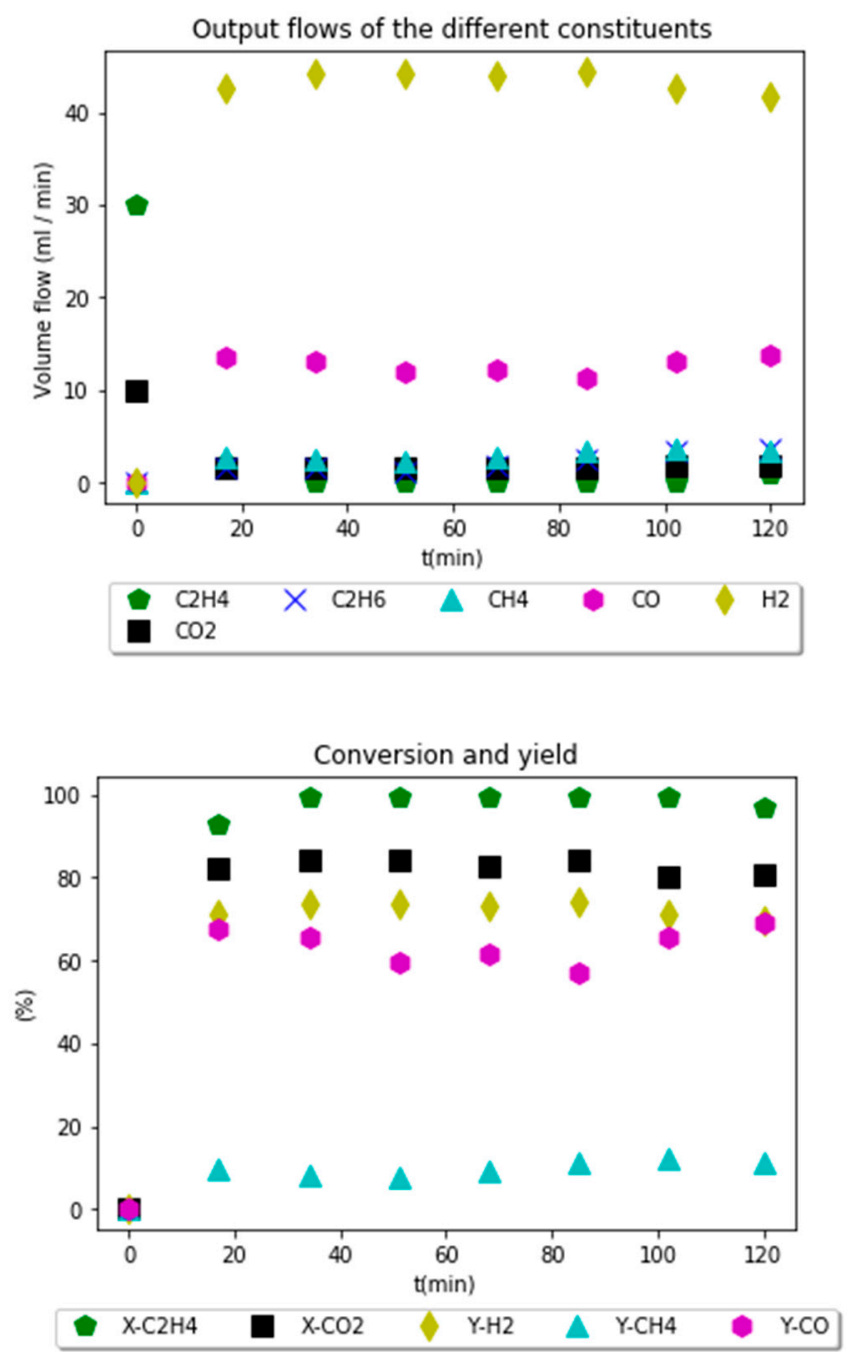

Figure 14. Experimental results for DR reaction using Ni-UGSO $13 \%$ at $650{ }^{\circ} \mathrm{C}$ for $2 \mathrm{~h}$ TOS.

We observed that, during the first $100 \mathrm{~min}$, the conversion of $\mathrm{C}_{2} \mathrm{H}_{4}$ is near $100 \%$ and starts slightly decreasing during the last $20 \mathrm{~min}$. Hydrogen yield is constant for $120 \mathrm{~min}$ and equal to $65 \%$ (Figure 14), and the rate of carbon formation is high and equal to $2.25 \mathrm{~g}_{\mathrm{C}} \cdot \mathrm{g}_{\mathrm{cat}}{ }^{-1} \cdot \mathrm{h}^{-1}$. These high and constant rates 
of carbon and $\mathrm{H}_{2}$ formation are due to the high activity of the catalyst and can be explained by the following: the $\mathrm{H}_{2}$ formed contributes to the additional activation of the catalyst through the reduction of iron oxides. This is proven by the presence of Fe and Ni metal peaks and the disappearance of iron oxide peaks on used catalyst XRD (Figure 15). It has been demonstrated that the carbon under the form of catalytically induced CNF itself has catalytic properties [4]. Although the activity measured through carbon TOF per mass of CNF is lower, if the TOF is calculated per mass of carbides content of the $\mathrm{CNF}$, it is shown to be higher. This explains, at least partially, why the catalytic activity remains high even when the catalyst surface is covered by CNF.

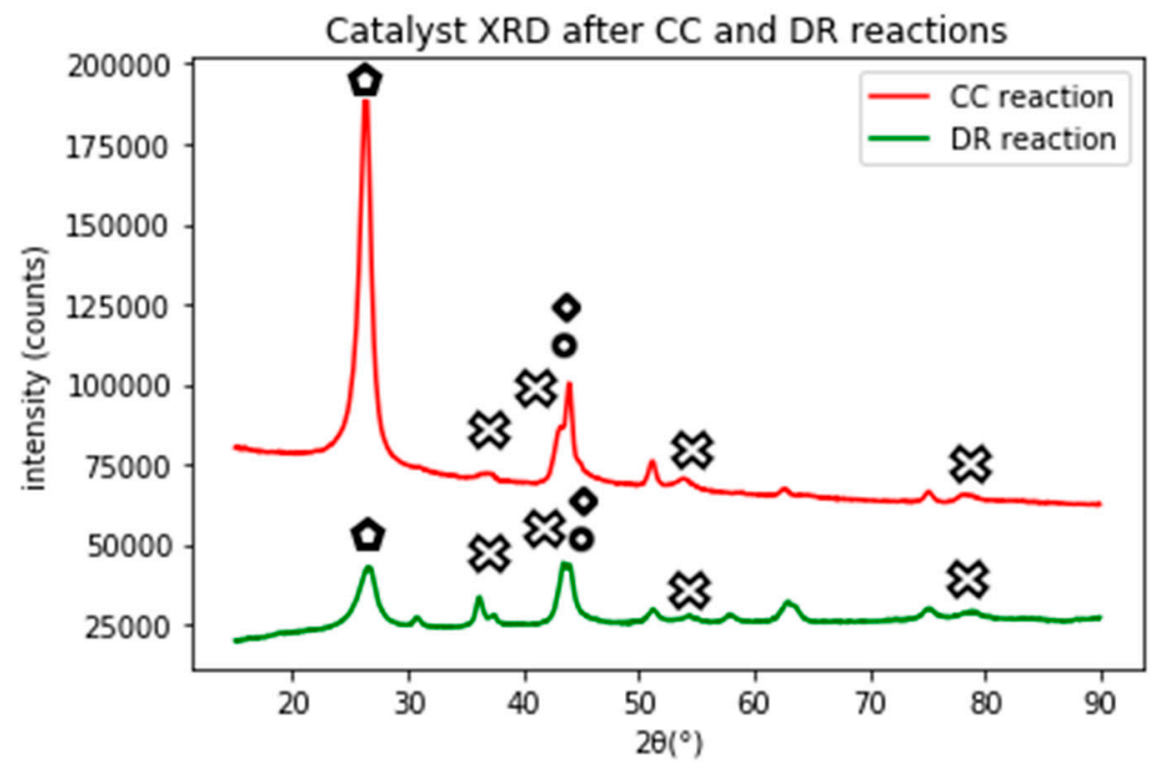

Figure 15. XRD analysis of Ni-UGSO $13 \%$ after the $\mathrm{CC}$ reaction at $750{ }^{\circ} \mathrm{C}$ and after the $\mathrm{DR}$ reaction at $650{ }^{\circ} \mathrm{C}$ for $2 \mathrm{~h}$ TOS.

The carbon formed was analyzed by SEM and it has been proven that it is mainly under the form of CNF (Figure 16).

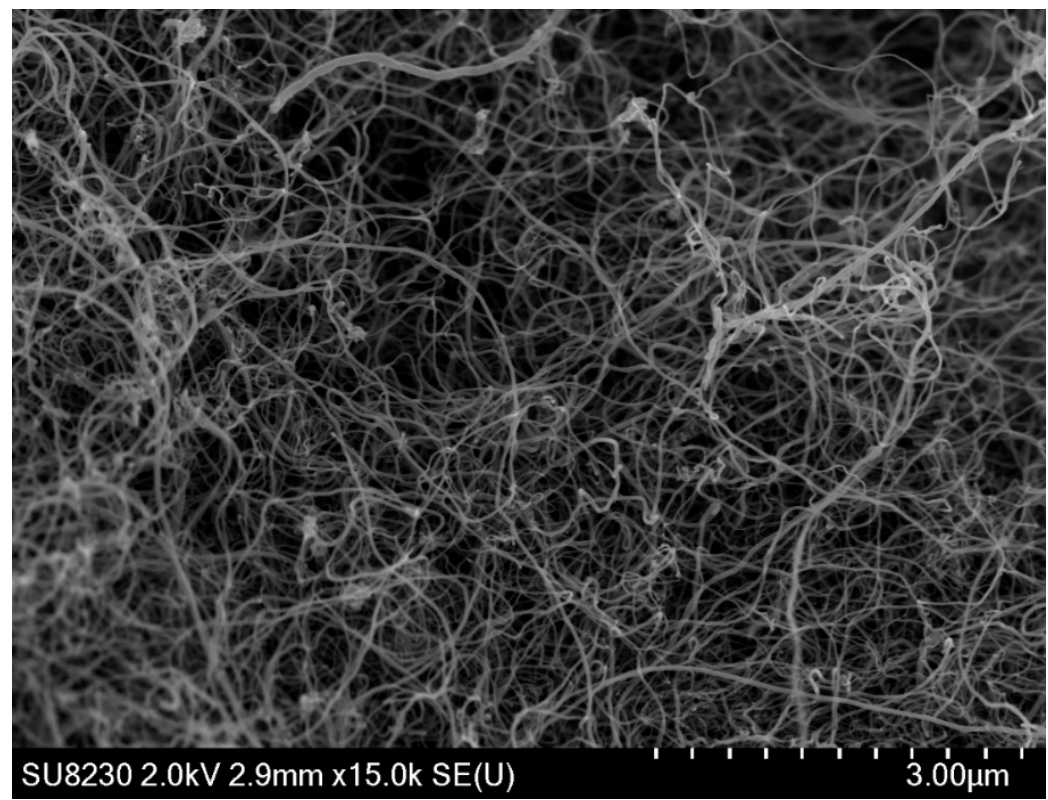

Figure 16. SEM analysis of CNF produced at $650^{\circ} \mathrm{C}$ using Ni-UGSO $13 \%$ for DR reaction for $2 \mathrm{~h}$ TOS. 


\subsection{Characterization of CNF and Spent Catalyst}

\subsubsection{XRD Analysis}

Figure 15 shows the XRD of deposited carbon on the used catalyst after the DR and CC reactions. The peak at $2 \theta=26^{\circ}$ confirms that the carbon formed is graphitic, no peaks of oxides have been detected, and only Ni and Fe were present in the patters, which proves that their oxides were reduced during the reactions. Carbide formation was expected because carbides are known to be the precursor of $\mathrm{CNF}$ especially with iron-based catalysts. $\mathrm{Fe}_{3} \mathrm{C}$ is metastable under the reaction conditions so it is decomposed to CNF and $\alpha$-Fe [35]. Nickel plays a key role in the formation of CNF because, when UGSO was used alone, catalyst activity was low [30]. When nickel was added, the quantity and quality of CNF were found to have improved. Nickel catalyzes the $\mathrm{C}-\mathrm{C}$ bond cleavage, thus producing carbon species radicals and atomic carbon that diffuses and dissolves in the iron to form a solid solution of iron carbides [36].

\subsubsection{TGA}

Figure 17 shows the results of TGA analysis. For the DR sample, at T up to $450{ }^{\circ} \mathrm{C}$, a mass gain of $0.25 \%$ was detected. Between $450{ }^{\circ} \mathrm{C}$ and $765^{\circ} \mathrm{C}$, there was a mass loss of about $60 \%$; finally, between $765^{\circ} \mathrm{C}$ and $890^{\circ} \mathrm{C}$, a mass gain of $0.05 \%$ was observed.
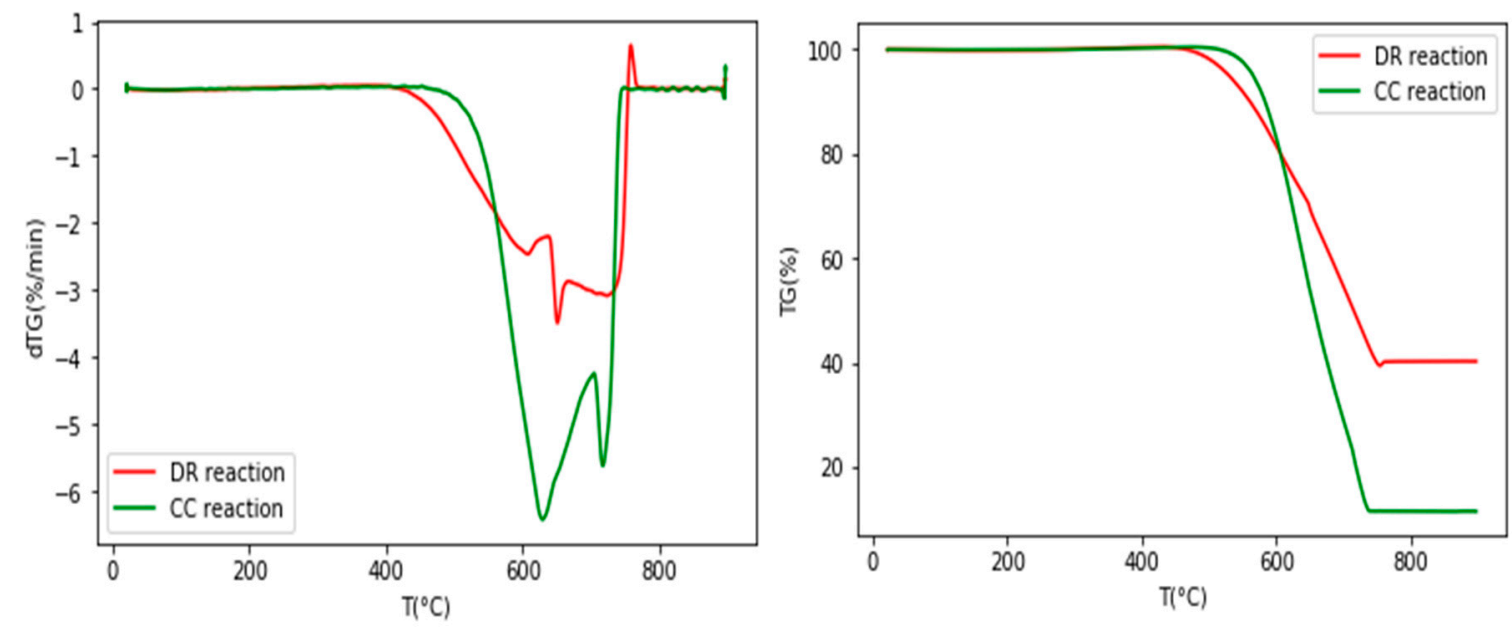

Figure 17. TGA analysis of Ni-UGSO $13 \%$ after $\mathrm{CC}$ reaction at $750{ }^{\circ} \mathrm{C}$ and after DR reaction at $650{ }^{\circ} \mathrm{C}$ for $2 \mathrm{~h}$ TOS.

For the CC sample, up until $500{ }^{\circ} \mathrm{C}$, a mass gain of $0.23 \%$ was measured. From $500{ }^{\circ} \mathrm{C}$ to $750{ }^{\circ} \mathrm{C}$, there was a mass loss of $88.62 \%$ and, finally, between $750{ }^{\circ} \mathrm{C}$ and $900{ }^{\circ} \mathrm{C}$, a mass gain of $0.05 \%$ was observed.

The higher the temperature of oxidation, the higher the degree of structural order. Thus, as can be seen in Figure 17, the oxidation of CNF produced by DR (CNF-DR) begins at a temperature lower than that in the case of $\mathrm{CNF}$ formed by CC (CNF-CC) $\left(450{ }^{\circ} \mathrm{C}\right.$ vs. $\left.500{ }^{\circ} \mathrm{C}\right)$. In the literature, it has been reported that the oxidation of graphite and $\mathrm{C}_{60}$ in TGA occurs at $645{ }^{\circ} \mathrm{C}$ and $420{ }^{\circ} \mathrm{C}$, respectively [37]. The oxidation temperature of CNF-CC is similar to that reported for CNT [38] and higher than that reported by Sui et al. [39]. They are all lower than the graphite oxidation temperature. Serp et al. [40] have confirmed that CNT and CNF are more reactive than graphite. They have shown that CNF samples with $10 \%$ of remaining metal (produced from ethylene on $\mathrm{Fe} / \mathrm{SiO}_{2}$ catalysts) present a maximum gasification rate at $650{ }^{\circ} \mathrm{C}$. The single-wall carbon nanotube (SWCNT), which is the carbon nanostructure that has the least remaining metal percentage (less than $1 \%$ of metal) and the least defects on its surface, presents a maximum gasification rate at $800{ }^{\circ} \mathrm{C}$. MWCNT, with $3 \%$ and $7.5 \%$ of residual metal, presents a maximum rate at $650{ }^{\circ} \mathrm{C}$ and $550{ }^{\circ} \mathrm{C}$, respectively. According to these 
findings, the presence of defects on the CNF surface and the presence of residual metal within the carbon nanostructures that can catalyze carbon gasification cause a shift to lower temperatures. While the oxidation resistance of the DR carbon and the CC carbon is different, we can say that either CNF-DR carbon is more structured than CNF-CC, or that it contains more metal, or even that their surfaces are not the same, which means that they are two distinct types of CNF. The TEM analyses reported below help us to identify the type of CNF produced. It is well known that there are different types of $\mathrm{CNF}$ depending on the arrangement of the graphene plans. Accordingly, $\mathrm{CNF}$ are classified into three categories: platelets, fishbone, and stacked-cup CNF [2].

\subsubsection{SEM-EDX Analysis}

SEM images have shown that, in this experiment, the carbon is under the form of filaments of varying diameters. For CNF-DR, the diameter range is $15-50 \mathrm{~nm}$ (Figure 18) and for CNF-CC it is 25-75 nm (Figure 19). Using backscattered electron imaging (Figure 20), we can see that the metal particles are located on the top of the nanofilaments.

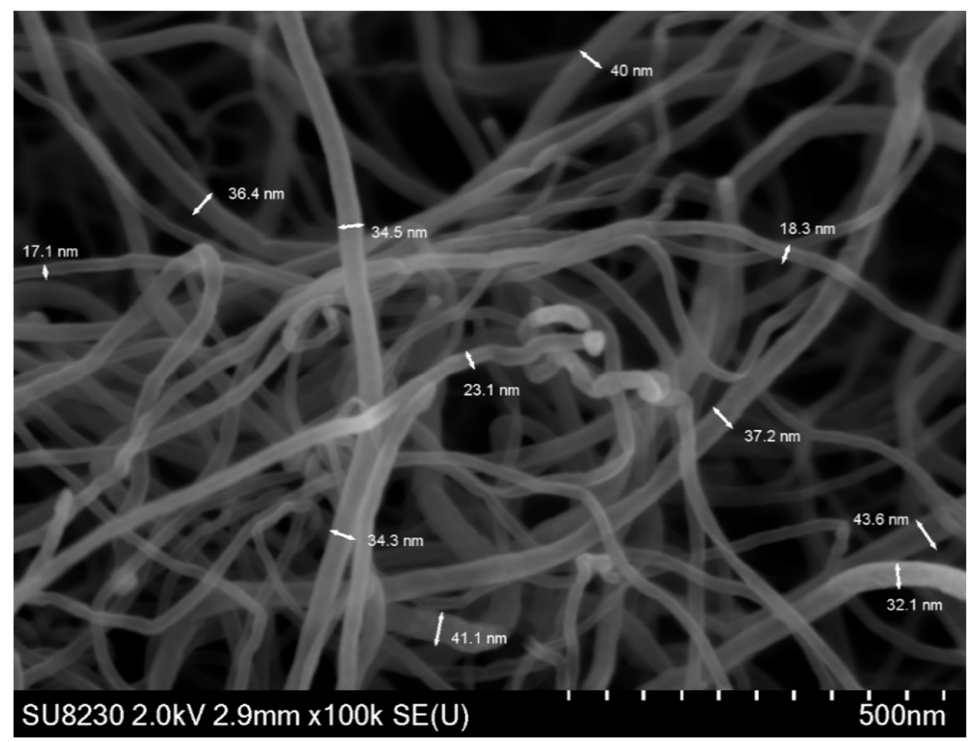

Figure 18. SEM analysis of carbon deposited on Ni-UGSO 13\% after DR reaction at $650{ }^{\circ} \mathrm{C}$ for $2 \mathrm{~h}$ TOS.

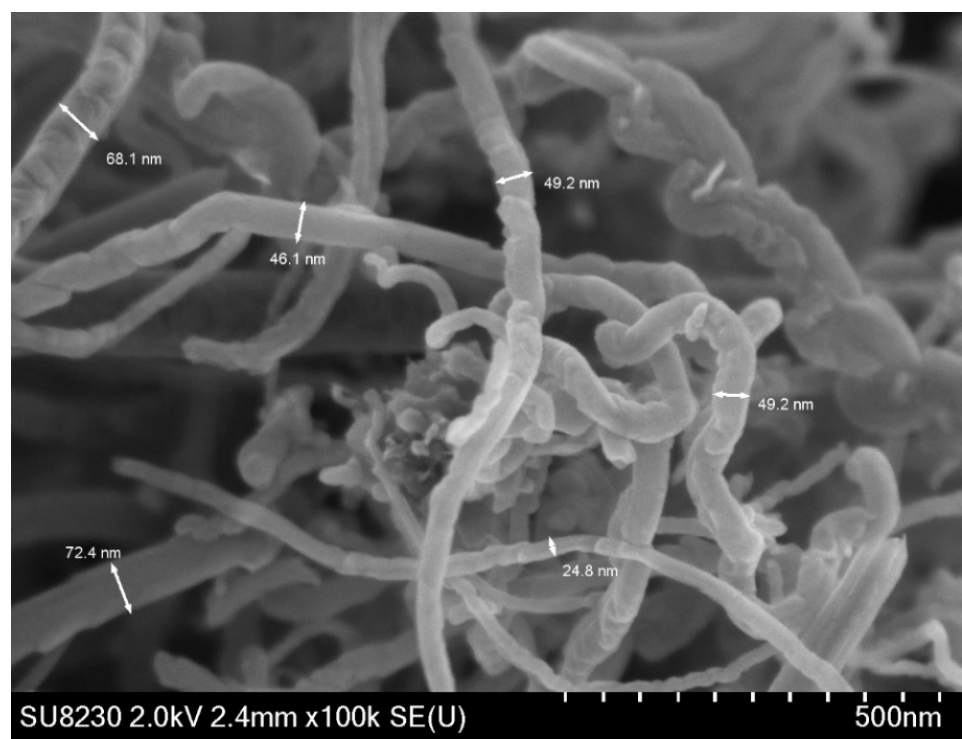

Figure 19. SEM analysis of carbon deposited on Ni-UGSO $13 \%$ after the $\mathrm{CC}$ reaction at $750{ }^{\circ} \mathrm{C}$ for 2 h TOS. 


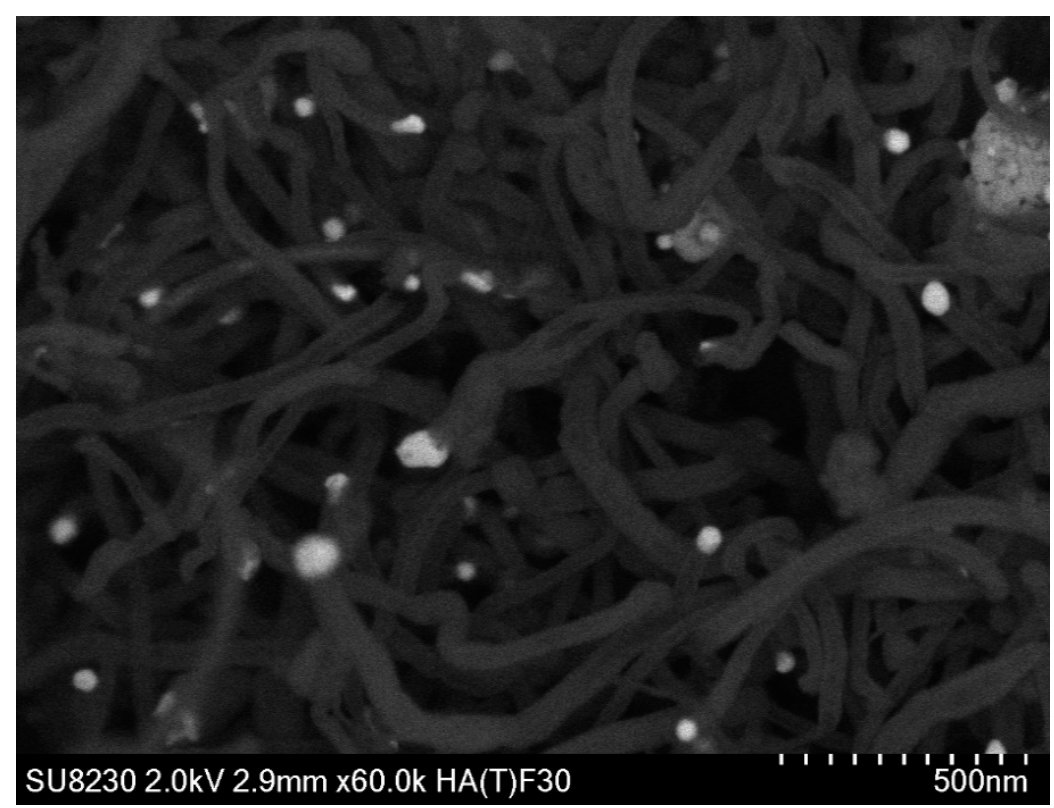

Figure 20. SEM analysis (using backscattered electron imaging) of carbon deposited on Ni-UGSO 13\% after DR reaction at $650{ }^{\circ} \mathrm{C}$ for $2 \mathrm{~h}$ TOS.

The EDX images presented in Figures 21 and 22 give a chemical analysis of the spent catalyst and carbon deposited. We notice on the spectrum that the peaks of carbon are intense for both reactions, which proves the existence of carbon corresponding to CNF, as we can see on the SEM images.

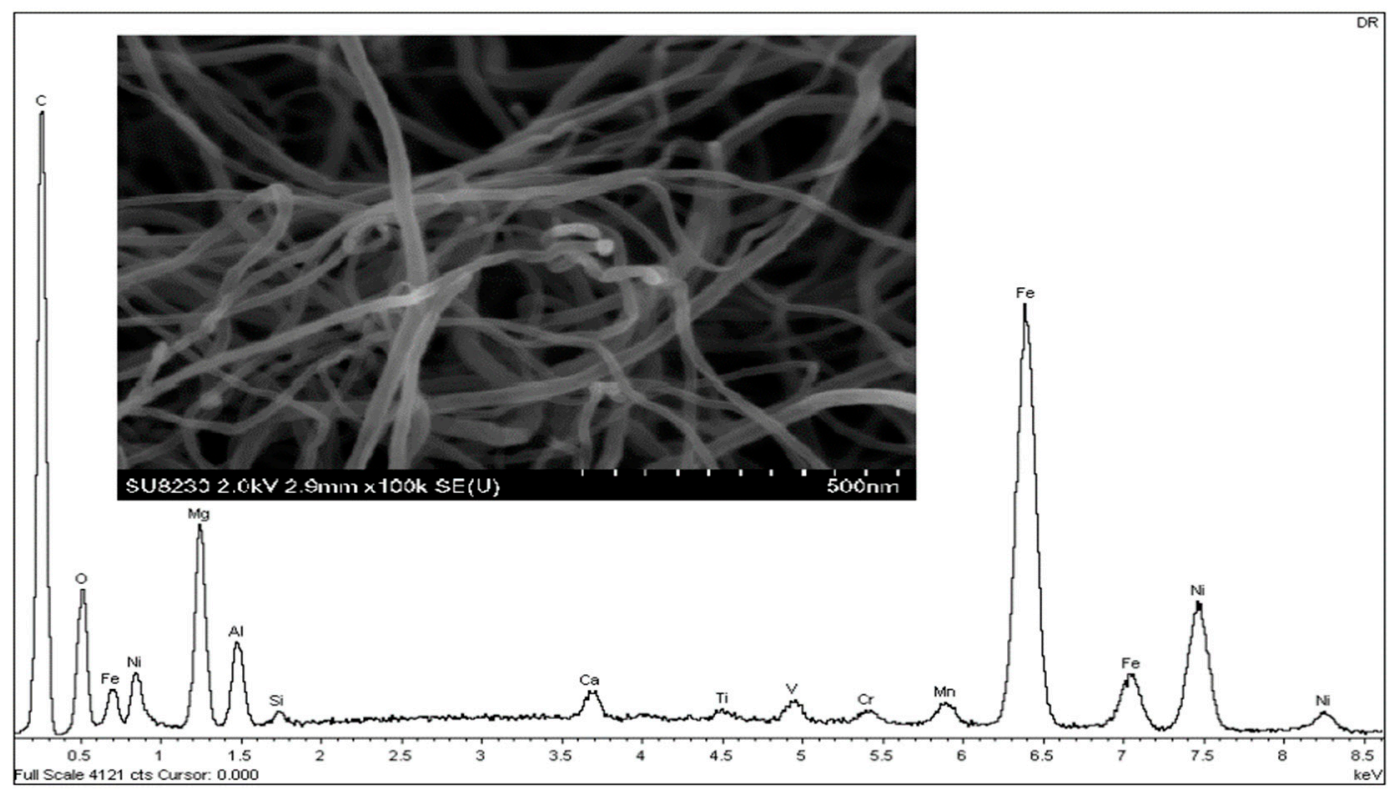

Figure 21. EDX analysis of carbon deposited on Ni-UGSO $13 \%$ after the DR reaction at $650{ }^{\circ} \mathrm{C}$ for $2 \mathrm{~h}$ TOS. 


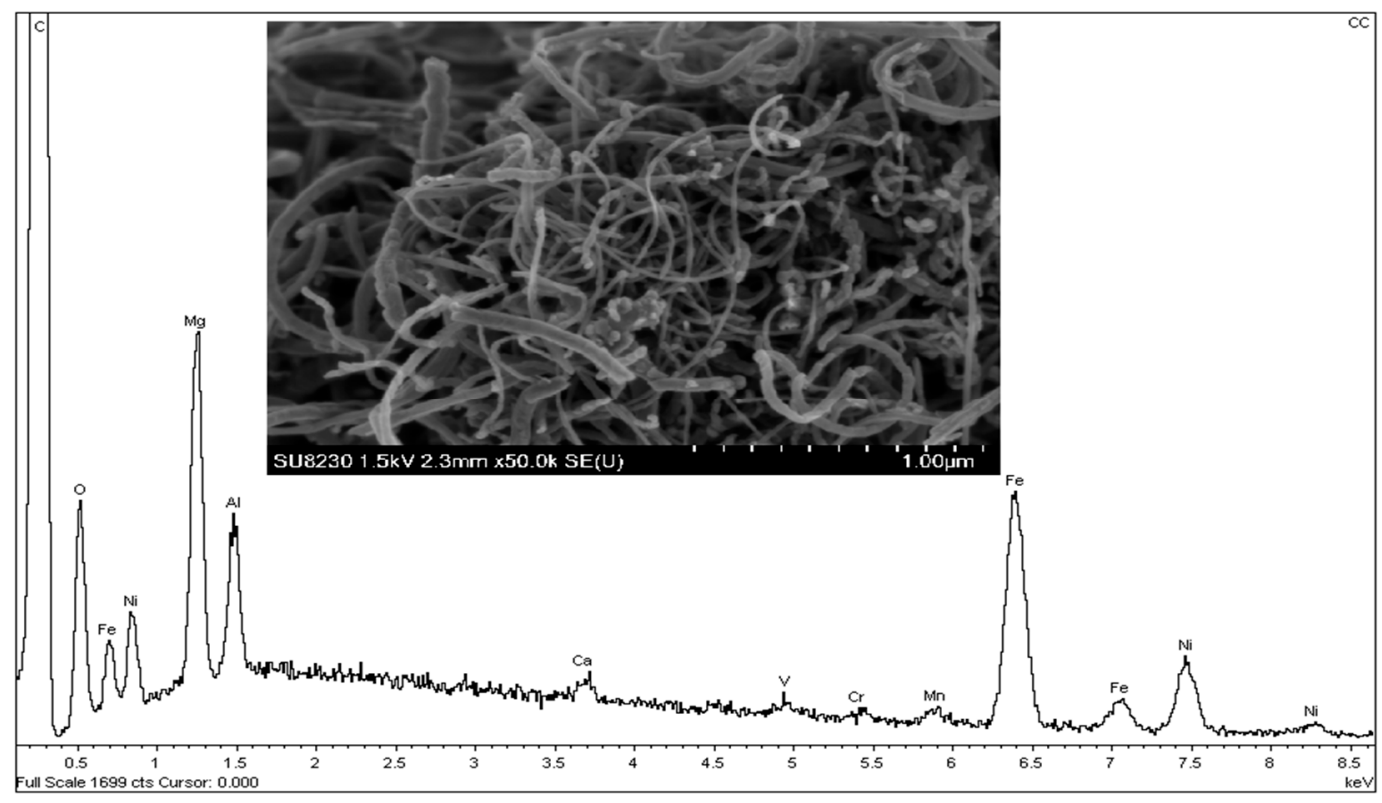

Figure 22. EDX analysis of carbon deposited on Ni-UGSO $13 \%$ after the $\mathrm{CC}$ reaction at $750{ }^{\circ} \mathrm{C}$ for $2 \mathrm{~h}$ TOS.

\subsubsection{TEM-EDX Analysis}

\section{- DR Reaction Sample}

Examination of the carbon formed in TEM demonstrated that the carbon formed consists entirely of cylindrical and straight CNF. However, all CNF produced are of the fishbone type (graphene sheets at a certain angle relative to the hollow core fiber main axis). Romero et al. [29] have indicated in their article that Fe-based catalysts are responsible for the growth of two types of CNF, tubular (sheets parallel to fiber axis), and platelets; while Ni-based catalysts are responsible for the growth of fishbone type CNF only. However, in an earlier work of our research group [15] where steel was used as a dry reforming catalyst to produce CNF, it has been found that different forms of CNF were formed during the reactions, including fishbone ones. Yu et al. [32] have done a study in conditions similar to ours, which consists of decomposing a $\mathrm{C}_{2} \mathrm{H}_{4} / \mathrm{H}_{2} / \mathrm{CO}$ mixture with a Ni-Fe bimetallic catalyst and have found that the CNF formed during their study were of the fishbone type. They have reported that the fishbone is probably formed when a Boudourd reaction took place. In light of these results, we can deduce that the catalyst is not the only factor that influences the type of carbon formed; other factors, such as the type of gas supplied and the temperature, also have an influence as discussed further in Section 2.5.

When the graphitic sheets stack with one another, the angle formed between the sheets and the fiber axis was not always the same for all of the produced CNF. Different angles $\left(11^{\circ}, 17^{\circ}, 23^{\circ}\right)$ are observed. It also seems that the diameter of the hollow core depends on this angle: the bigger the angle, the smaller the diameter (Figure 23). Since the catalyst's structure changes over TOS, it is rather impossible to control the width of the CNF as it is also discussed further on (Section 2.5). 


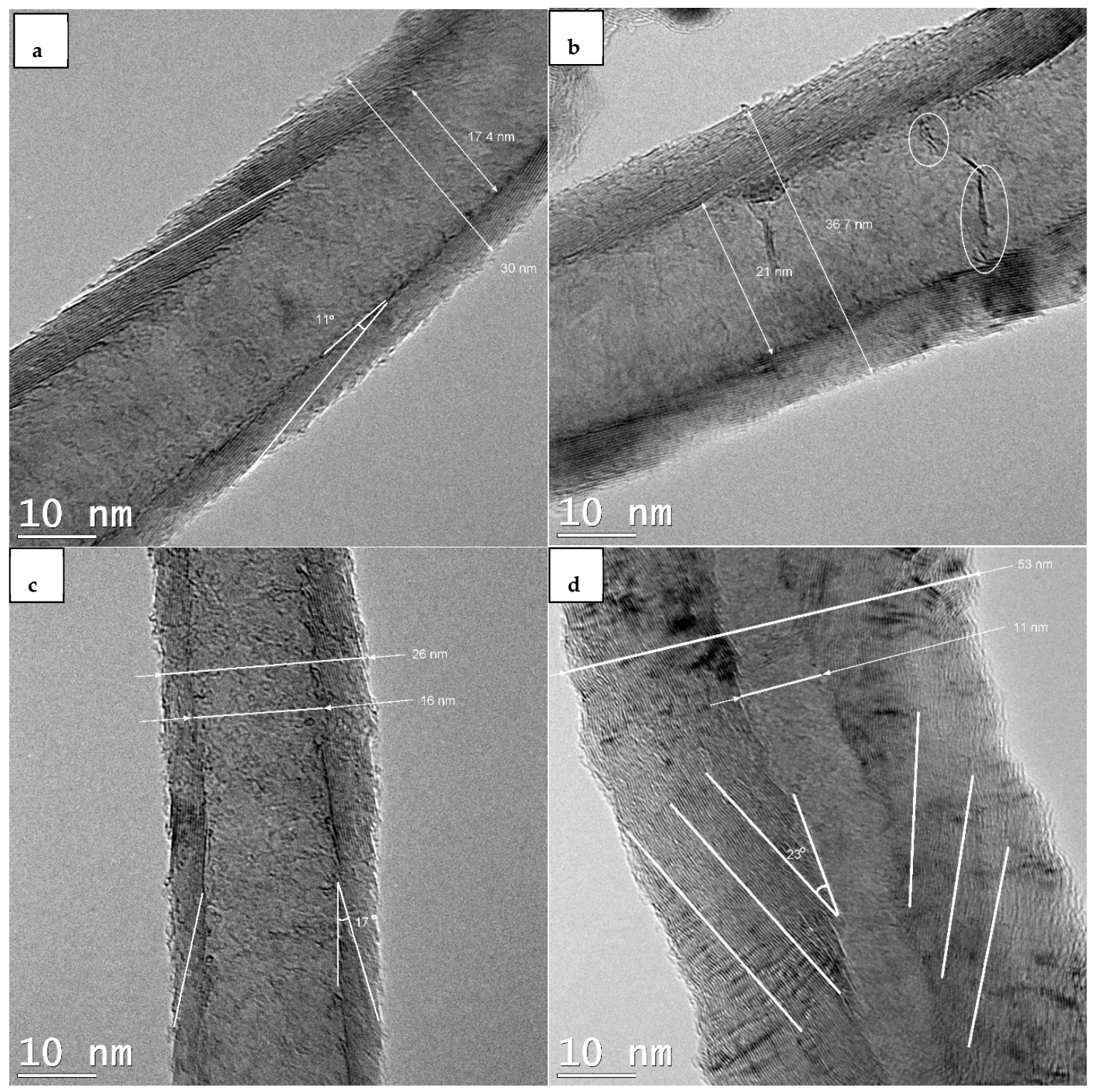

Figure 23. TEM analysis of carbon deposited on Ni-UGSO $13 \%$ after the DR reaction at $650{ }^{\circ} \mathrm{C}$ for 2 $\mathrm{h}$ TOS, (a) CNF with $\mathrm{d}=30 \mathrm{~nm}$, (b) CNF with $\mathrm{d}=36.7 \mathrm{~nm}$, (c) CNF with $\mathrm{d}=26 \mathrm{~nm}$, (d) CNF with $\mathrm{d}=53 \mathrm{~nm}$.

The distance between the graphitic sheets is $0.340 \mathrm{~nm}$ (Figure 24), which is higher than the corresponding distance of graphite $(0.335 \mathrm{~nm})$. This means that CNF have structural defects and their structure is only ordered locally, not globally [29]. These defects are shown in as waved lines. The fact that the CNF are less ordered and have defects has been verified by TGA profiles (Figure 17), where the latter demonstrates that lower temperatures are necessary to oxidize CNF. Some zones that are darker than others can also be observed; they are due to layers not being stacked identically, and whose local density is different. The degree of graphitization $(g)$ is calculated using this Equation: $d_{h k l}=3.354+0.086(1-g)$, where $\mathrm{d}_{\mathrm{hkl}}$ is the interplanar distance [41]. Thus, the $g$-value of the CNF produced in this study is $g=46.5 \%$. Romero et al. [29] have found that CNF produced from ethylene decomposition over a Fe-Ni-based catalyst have an interplanar distance of $3.42 \AA$, therefore $g=23 \%$, which means that they are less graphitized than those obtained in this work. 


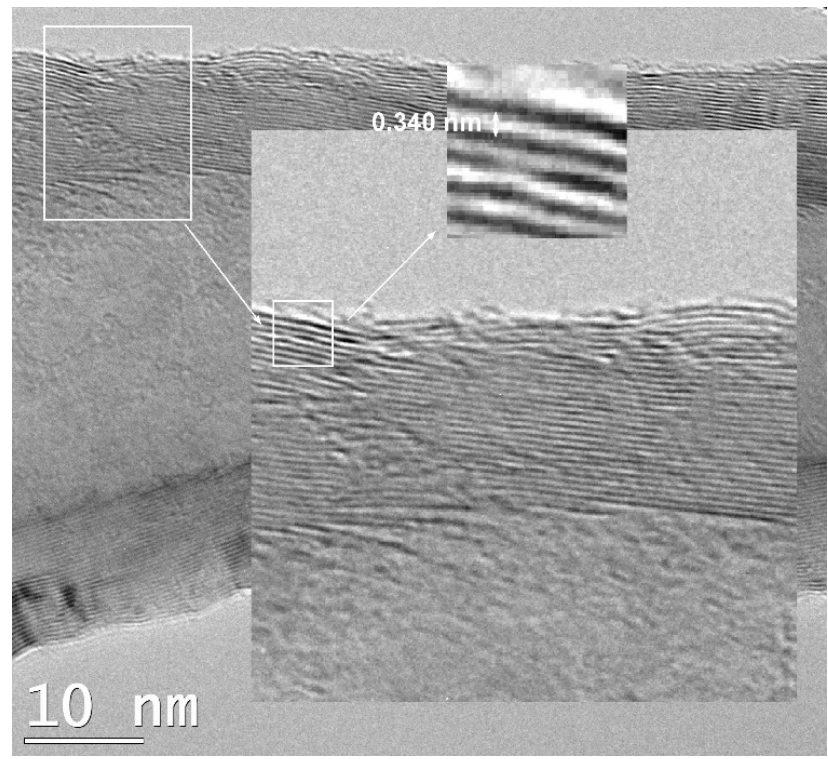

Figure 24. Interplanar distance of graphene sheets.

SAED analysis confirmed that the interplanar distance of CNF is $0.340 \mathrm{~nm}$. The second $\mathrm{d}_{\mathrm{hkl}}$ can be attributed to planes (102), (220), and (031) of $\mathrm{Fe}_{3} \mathrm{C}$ according to JCPDF File \# 35-0772, or to planes (111) and (110) of $\mathrm{Ni}$ and $\mathrm{Fe}$, respectively. From the presence of $\mathrm{Fe}_{3} \mathrm{C}$, it can be deduced that $\mathrm{CNF}$ have grown on Fe. The existence of the Ni atoms in the metallic particles at the bottom of the CNF, as it is proven by SAED (Figure 25) and confirmed by the EDX analysis (Figure 21), confirms that the Ni has mainly participated in one of the stages of the growth of the CNF, which is the decomposition of the $\mathrm{HC}$, while the iron is the main contributor in the second and third stages (dissolution and precipitation). In fact, it is known that $\mathrm{Ni}$ and Fe differ in their ability to decompose $\mathrm{HC}$ and solubilize carbon. Ni rapidly dehydrogenates the adsorbed HC while Fe is slower, and iron solubilizes carbon better than $\mathrm{Ni}$. Indeed, the solubility of the carbon in the $\mathrm{Ni}$ in the range of temperature at which we worked is very low. Lander et al. [42] have experimentally developed an Equation that gives the solubility of carbon in nickel between $700{ }^{\circ} \mathrm{C}$ and $1300^{\circ} \mathrm{C}$, which is as follows: $\ln S=2.48-\frac{4.880}{T}$, where $\mathrm{S}$ is the solubility in grams of carbon per $100 \mathrm{gr}$ of nickel and the temperature is in ${ }^{\circ} \mathrm{C}$. The $\mathrm{S}$ value at $700{ }^{\circ} \mathrm{C}$ is relatively low (2.5\%). This will also be discussed further in Section 2.5.

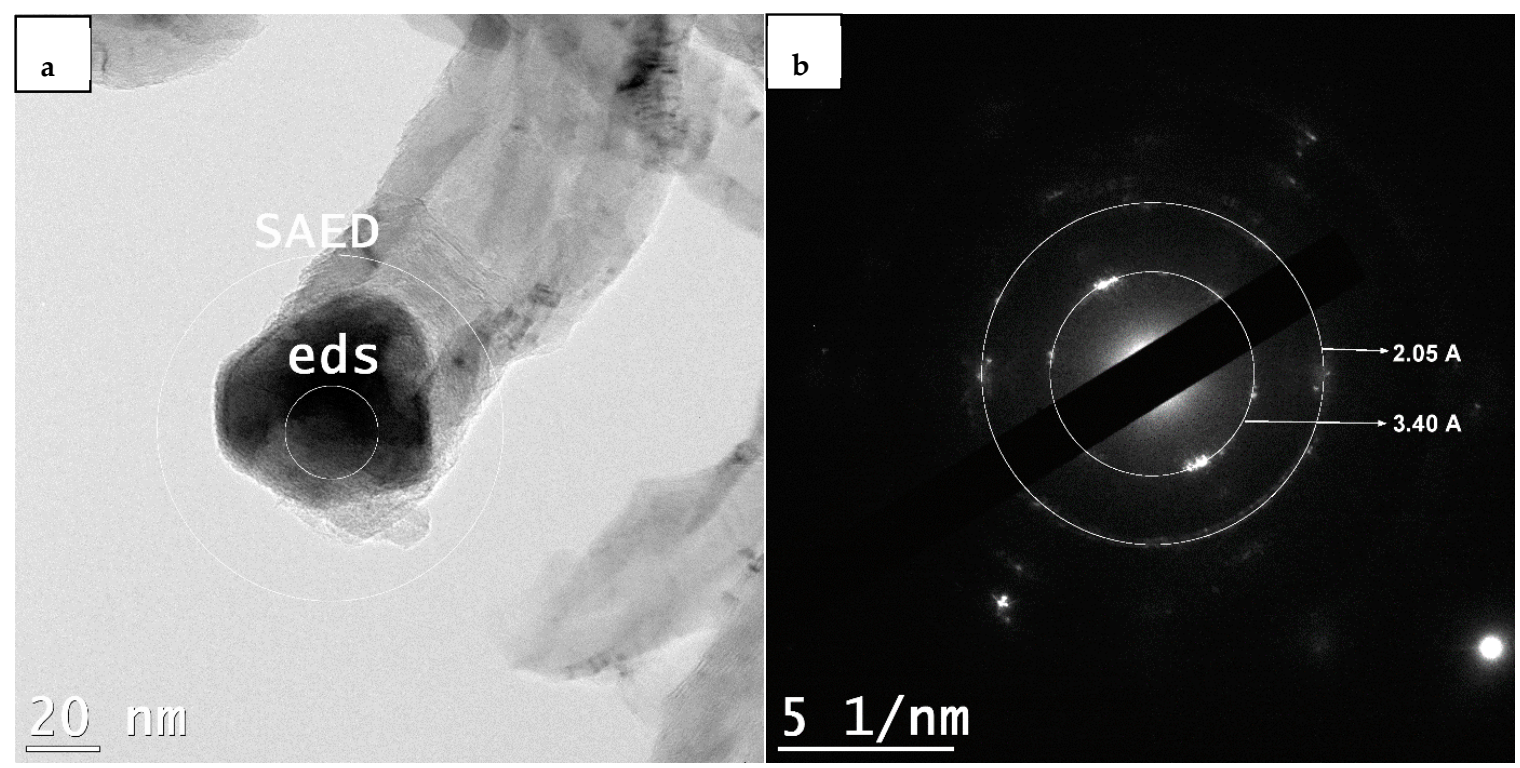

Figure 25. (a) Metallic particle at the tip of CNF. (b) SAED of this particle. 
- CC Reaction Sample

For the CC reaction, we observed that there are different types of CNF, such as the tubular shape (layers are parallel to fiber axis like MWCNT) with a hollow core (Figure 26b,d), where we can also observe that some layers have torn ends. It seems that the sheets tended to connect to fill the inside of the CNF structure. Another type of structure is the bamboo type (Figure 26c). We were also able to observe that CNF formed with irregular stacking of graphene planes (Figure 26a), and we can observe that the graphene planes started out parallel to one another and that the angle of inclination with the fiber axis subsequently changed. The appearance of these CNF is quite similar to those formed by the decomposition of $\mathrm{C}_{2} \mathrm{H}_{4} / \mathrm{H}_{2}$ over Fe:Ni catalyst studied by Park and Baker [43].
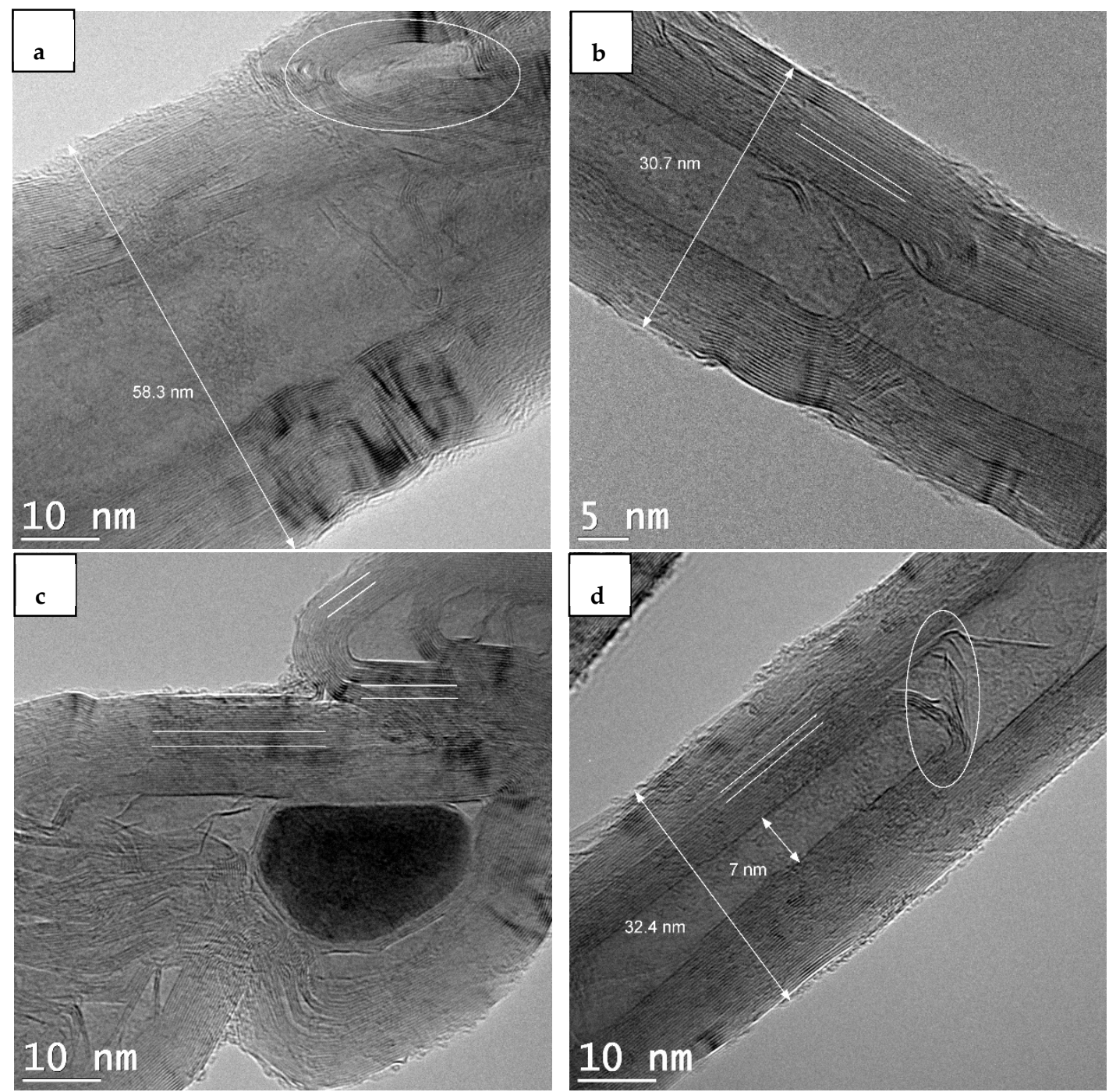

Figure 26. TEM analysis of carbon deposited on Ni-UGSO $13 \%$ after CC reaction at $750{ }^{\circ} \mathrm{C}$ for $2 \mathrm{~h}$ TOS, (a) CNF formed with irregular stacked graphene planes, (b) and (d) tubular CNF with hollow core, (c) bamboo CNF.

In Figure 27, we observe that the metal particle is not on the tip of the filament contrary to what was found in DR, but it is encapsulated inside the filament. This could be explained by the fragmentation of the main particle, as its fragments could have been entrained within the body structure of the filament during the growth phase. The same behavior was found by Park and Baker [43] who worked in conditions similar to those used for this work (decomposition of $\mathrm{C}_{2} \mathrm{H}_{4}$ over Ni-Fe catalyst). The metal particle that was encapsulated by the $\mathrm{CNF}$ during the $\mathrm{CC}$ reaction appears to have a smooth globular 
morphology, in contrast to the structure of the catalyst particles at the end of the CNF produced in the DR reaction, which have more angular forms.
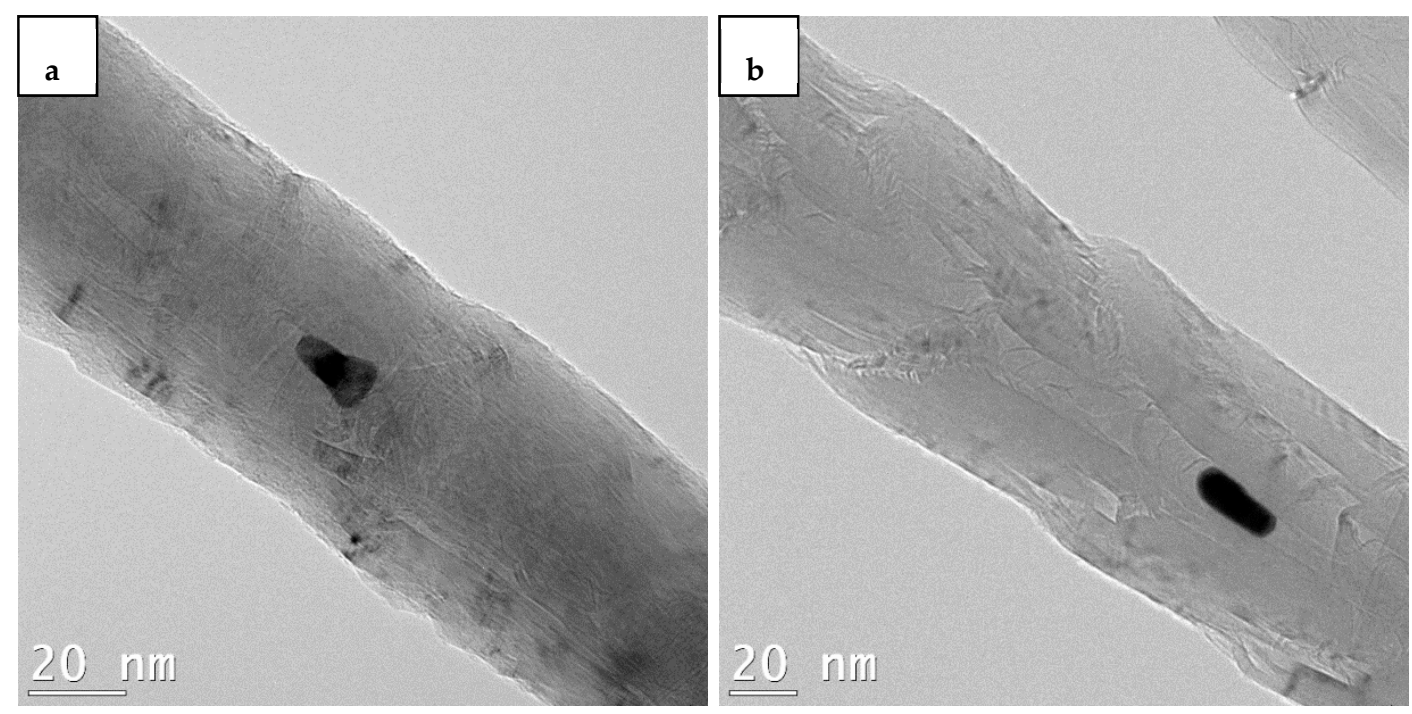

Figure 27. TEM analysis showing a catalyst particle inserted in two different nanofilaments.

The EDX analysis presented in Figure 28 shows Fe and Ni peaks in the pattern as well as C peak, which proves that the metallic particle is composed of both metals and encapsulated by carbon.

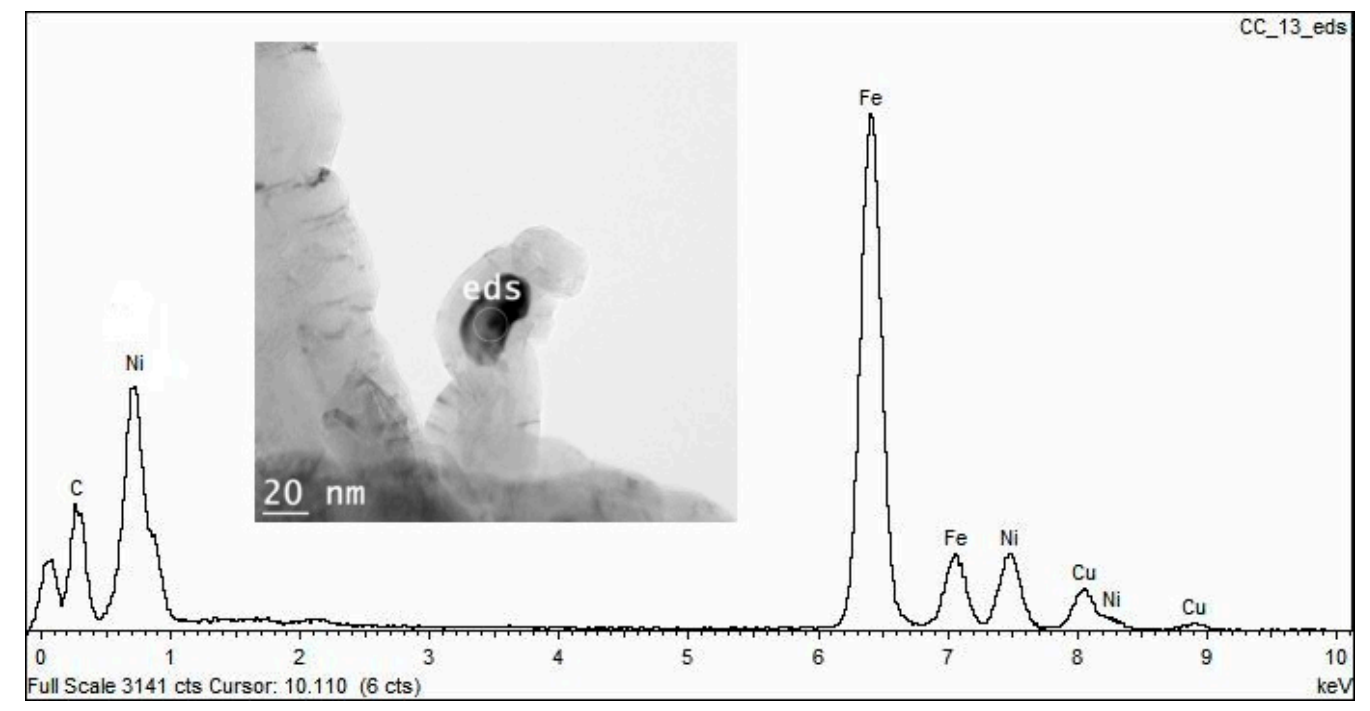

Figure 28. EDX analysis of carbon deposited on Ni-UGSO $13 \%$ after CC reaction at $750{ }^{\circ} \mathrm{C}$ for $2 \mathrm{~h}$ TOS.

\subsection{Mechanistic Understanding for the Growth of CNF}

The results of this study, which aimed to test the catalytic performance of a new catalyst derived from a mining residue (Ni-UGSO), have shown that Ni-UGSO is also a good catalyst for CNF production from ethylene cracking and dry reforming.

The influence of the catalyst composition as well as of the precursor gas composition and reaction conditions are discussed below.

\subsubsection{Influence of the Catalyst on the Growth of CNF}

The effects of $\mathrm{Ni}$ and $\mathrm{Fe}$ on the growth of CNF is different depending on whether it is a CC reaction (decomposition of $\mathrm{C}_{2} \mathrm{H}_{4}$ ) or a DR reaction (decomposition of $\mathrm{C}_{2} \mathrm{H}_{4}$ and disproportionation of $\mathrm{CO}$ ). 
Park et al. [43] have mentioned in their work that Ni-based catalysts are good for the decomposition of ethylene but were not as potent for catalyzing the Boudouard reaction, whereas Fe-based catalysts exhibited the opposite behavior. This fact was verified by our work, where we found that $\mathrm{Ni}$ is responsible for ethylene decomposition while $\mathrm{Fe}$ is responsible for the growth of CNF. They studied a bimetallic Ni-Fe catalyst for the decomposition of $\mathrm{C}_{2} \mathrm{H}_{4}$ and $\mathrm{CO}$ in the temperature range $600-725^{\circ} \mathrm{C}$, and they proved that increasing the ambient temperature improves the decomposition of $\mathrm{C}_{2} \mathrm{H}_{4}$ while the Boudouard reaction is favored thermodynamically by temperatures of around $550{ }^{\circ} \mathrm{C}$.

It has also been found that the crystallographic orientation of the metal atoms plays an important role in the ability of the catalyst to decompose the reactive gases [44]. Zhu et al. [45] showed that the $\mathrm{Ni}$ (111) plane adsorbs ethylene and acetylene dissociatively, which was proven in this work by SAED results where the $\mathrm{Ni}$ (111) facet was found on the metal particle on the top of CNF (Figure 25). Their calculations show that the rate of diffusion of carbon on the $\mathrm{Ni}$ (110) plane is the fastest step. However, the carbon deposited on the facet (110) is poorly crystallized because the distance of this plane does not correspond to that required for forming a graphite network. To form a good crystalline carbon structure, the atoms resulted from the decomposition of HC must first diffuse through Ni to dissolve and then precipitate onto the adequate $\mathrm{Fe}$ (110) facet (Table 9), which is required to form a graphite network. The energy difference between poor and well-crystallized carbon is the driving force that leads to transfer from one side of a metal to another [44].

Table 9. Indexation of D-spacing measured by SAED.

\begin{tabular}{|c|c|c|}
\hline Measured D-Spacing (̊̊) & Indexation [43] & Theoretical d-Spacing (̊̊) [43] \\
\hline \multirow{5}{*}{2.05} & $(111) \mathrm{Ni}$ & 2.03 \\
\hline & (110) Fe & 2.04 \\
\hline & (102) $\mathrm{Fe}_{3} \mathrm{C}$ & 2.07 \\
\hline & (220) $\mathrm{Fe}_{3} \mathrm{C}$ & 2.03 \\
\hline & (031) $\mathrm{Fe}_{3} \mathrm{C}$ & 2.01 \\
\hline 3.40 & (200) carbon & 3.35 \\
\hline
\end{tabular}

\subsubsection{Influence of Catalyst Particle Sizes on the CNF Diameter}

Rodriguez [46] has studied the interaction between a metallic surface and carbon. Figure 29 is a schematic representation of the forces involved in the interaction of a metal catalyst particle with a graphite support in the presence of a gaseous environment. The contact angle $\theta$ is determined by the surface energy of the graphite support $\left(\mathrm{Y}_{\mathrm{SG}}\right)$, the surface energy of the metal $\left(\mathrm{Y}_{\mathrm{MG}}\right)$, and the metal-graphite interfacial energy $\left(\mathrm{Y}_{\mathrm{MS}}\right)$, and is expressed in terms of Young's Equation:

$$
\mathrm{Y}_{\mathrm{SG}}=\mathrm{Y}_{\mathrm{MS}}+\mathrm{Y}_{\mathrm{MG}} \cos \theta
$$

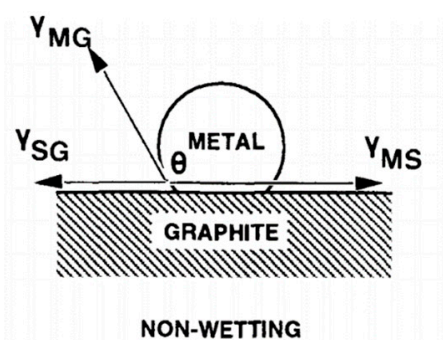

(a)

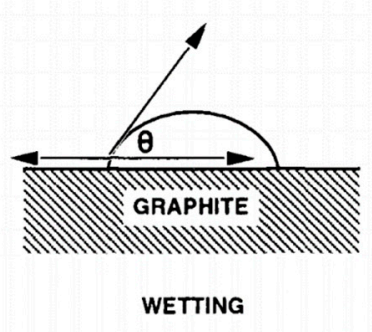

(b)

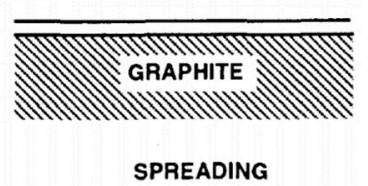

(c)

Figure 29. Interaction between surface metal and graphite [46].

It presents changes in the shape of the metal particles as a function of the catalyst wetting degree on the graphite: 
(a) When weak forces occur between the metal and the graphite, the resulting contact angle is higher than $90^{\circ}$ and there is no wetting;

(b) When strong forces occur between the two components, the contact angle is lower than $90^{\circ}$ and wetting occurs;

(c) When the adhesion exceeds the cohesion inside the particle $\left(Y_{M S}>Y_{S G}+Y_{M G}\right)$, the metal spreads over the graphite support surface [46].

Two forms of catalyst particles associated with nanotubular carbon products, which are clearly different from one another, are commonly observed and presented in the literature [47]: one is conical and the other one is spherical. The conical particles are usually found at the end of the nanofilaments, as it was proven in this work (Figure 25), and the almost spherical particles are observed at the end of the nanotubes [48]. For conical particles, the adhesion exceeds the cohesion inside the particle, which leads the metal to spread on the graphite surface and, after precipitation, the carbon takes the form of piled up stacked cones from the particle, determining the shape of the particle's bottom (Figure 30). In addition, when weak forces occur between the metal and the graphite and the contact angle is $>90^{\circ}$, nanotubes are formed (Figure 30).

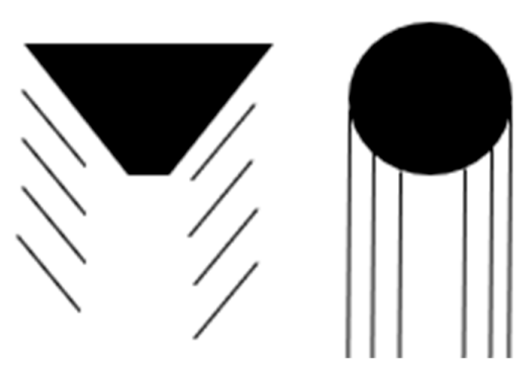

Figure 30. Conical and spherical metal particles on the top of CNF and CNT, respectively.

A sequence of "stop-action" images [48] shows that after a few seconds of initial growth, the particle is pushed upward by the carbon flux and lengthens. As growth continues, the surface in contact with the carbon begins to tilt upward until it forms a conical or tear-shaped form, the tip of the cone being oriented toward the growing carbon nanostructure and pointing in the direction of carbon diffusion. This observation leads to the conclusion that the commonly accepted belief that the catalyst particle determines the size and shape of the product is false. It is more likely the opposite [49].

\subsubsection{Influence of Gas Composition on CNF Growth}

The type of CNF formed is different for DR reactions and CC reactions; nevertheless, it also depends on other factors, namely the metal type and temperature. Luo et al. [50] have used $\mathrm{Ni}-\mathrm{La}_{2} \mathrm{O}_{3}$ in a flow of $\mathrm{CH}_{4} / \mathrm{N}_{2}, \mathrm{CO} / \mathrm{N}_{2}$, and $\mathrm{CO}_{2} / \mathrm{CH}_{4} / \mathrm{N}_{2}$, and they observed the production of both encapsulating carbon and CNF. The former was mostly formed in a $\mathrm{CH}_{4} / \mathrm{N}_{2}$ atmosphere whereas the latter was formed in a $\mathrm{CO} / \mathrm{N}_{2}$ or $\mathrm{CO}_{2} / \mathrm{CH}_{4} / \mathrm{N}_{2}$ atmosphere. These results are in accordance with our findings. When using only $\mathrm{C}_{2} \mathrm{H}_{4}, \mathrm{CNF}$ with irregular forms as well as encapsulated carbon was formed; while, during DR reactions (where CO is present), only fishbone-type CNF were formed.

In fact, the composition of the gas affects the composition of the surface of metal particles because of the preferential segregation behavior of one of these components, which affects the arrangement of the atoms in the crystallographic face. This critical characteristic determines the mode of adsorption and decomposition of the reactive gas [51]. It has been found that when $\mathrm{CO}$ is present in the reactive gas, particles tended to have a faceted form, which leads to the formation of fishbone CNF [51].

\subsubsection{CNF Precursor}

As it appeared on the images of the TEM analysis (Figure 25), the metal is located in the tip of carbon nanofilaments, which indicates that carbon has grown in a crystallographic face of the metal. 
Several authors have tried to find which phase is the one responsible for CNF growth. First, Baker et al. [52] report an activation energy that suggests that carbon diffuses through the reduced metal and, therefore, they indicate that the reduced metal is the growth crystal. Subsequently, Oberlin et al. [53] studied CNF growth on iron. They used TEM to identify growth crystals and reported that cementite and alpha iron were the only ones present in their work, which led them to conclude that not only is the active metal responsible for the growth of CNF but that it also contributed to the formation of metal carbides. In other research, in order to confirm which solid phase of iron is the most catalytic for carbon formation, Sacco et al. [36] worked on phase diagrams. They experimented by heating iron foils under a stream of hydrogen at $900 \mathrm{~K}$, then fed hydrocarbon gas mixtures of different compositions into the reactor for each experiment. They had a mass gain that corresponds to carbon formation only in the area where $\mathrm{Fe}_{3} \mathrm{C}$ is thermodynamically favored. Mass gain does not occur in $\alpha$-Fe region, which proves that carbides, at least initially, are needed for carbon formation. In another study, it was shown that $\mathrm{Fe}_{3} \mathrm{C}$ supported on graphite and exposed to acetylene did not catalyze carbon formation [27]. There are two assumptions to explain this: $\mathrm{Fe}_{3} \mathrm{C}$ does not catalytically break up acetylene, or it is necessary to have a $\mathrm{Fe}_{3} \mathrm{C} / \mathrm{Fe}$ dual phase metal interface to provide the solubility difference needed for carbon diffusion and thus the growth of the nanofilament. The results found in this work, which confirm the presence of the $\mathrm{Fe}_{3} \mathrm{C}$ peaks in the XRD pattern and SAED, confirm the assumption that the $\mathrm{Fe}_{3} \mathrm{C}$ is the responsible growth crystal for CNF.

\section{Experimental}

\subsection{Materials}

The targeted feedstock was gases derived from plastic pyrolysis, which are largely composed of unsaturated HC. The initial step, which is presented in this work, was the use of ethylene as a representative molecule.

UGSO - upgraded slag oxide-is a residue of the UGS process, which has been developed by RTIT to produce, from ilmenite, the world's richest titanium slag $\left(95 \% \mathrm{of}^{\mathrm{TiO}} \mathrm{O}_{2}\right)$. This mining residue is composed largely of $\mathrm{Fe}, \mathrm{Al}$, and $\mathrm{Mg}$ oxides as determined by inductively coupled plasma mass spectrometry (ICP-MS) elemental analysis shown in Table 10. To produce a reforming catalyst, the UGSO is doped with $\mathrm{Ni}$ [30]. Blank experiments have shown that UGSO itself has no significant catalytic activity [30].

Table 10. Average elemental analysis of the upgraded slag oxide (UGSO) residue [30].

\begin{tabular}{|c|c|c|c|c|c|c|c|c|c|c|c|c|c|c|}
\hline Component & $\mathrm{Fe}$ & Mg & Al & $\mathrm{Ca}$ & Mn & $\mathbf{V}$ & $\mathrm{Ti}$ & $\mathrm{Cr}$ & $\mathrm{Na}$ & $\mathrm{Si}$ & $\mathbf{K}$ & $\mathbf{P}$ & $\mathrm{Zr}$ & $\mathrm{Zn}$ \\
\hline$(\text { wt. } \%)^{a}$ & 31.26 & 17.49 & 5.35 & 1.07 & 1.01 & 0.90 & 0.60 & 0.51 & 0.17 & 0.08 & 0.02 & 0.004 & 0.01 & 0.01 \\
\hline
\end{tabular}

\subsection{Set-Up}

Reactions (DR, CC, and activation reaction) were conducted in a differential fixed-bed reactor, which is a quartz tube of approximately $25 \mathrm{~cm}$ of length and $15 \mathrm{~mm}$ of internal diameter, put in an oven with temperature control. The catalyst was deposited at the bottom of the tube between two pieces of quartz wool and placed in the oven. Gases were fed from commercial gas (supplied by Praxair) cylinders: $\mathrm{C}_{2} \mathrm{H}_{4}(99 \%), \mathrm{CO}_{2}(99 \%)$ for the DR reaction, $\mathrm{C}_{2} \mathrm{H}_{4}(99 \%), \mathrm{Ar}(99 \%)$ for CC reaction, and $\mathrm{H}_{2}(99 \%)$ and $\mathrm{Ar}(99 \%)$ for the activation reaction. Three AALBORG mass flow meters were used to control the gas flow at the inlet (Figure 31). The flow rate of the products was measured using a bubble flow meter and its composition was analyzed by gas chromatography (GC Varian CP-3800) with a measurement error varying between $1 \%$ and $2.5 \%$ depending on the analyzed gases (i.e., $\mathrm{H}_{2}$ had the highest error proven during calibration tests). 


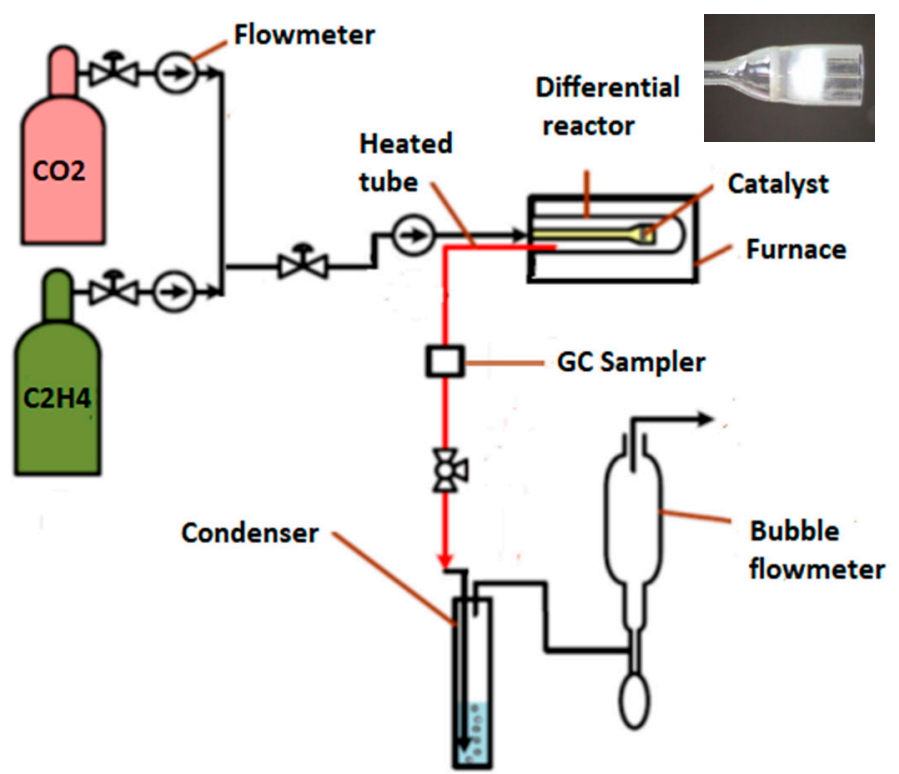

Figure 31. Reaction set-up [30].

\subsection{Experimental Methodology}

\subsubsection{Preparation of Ni-UGSO}

Ni-UGSO is prepared via a solid-state reaction developed by Chamoumi et al. [16]. In summary, UGSO was first milled and sieved in a $53 \mu \mathrm{m}$ sieve, which was the smallest size obtained with our dry powder sieving equipment. Nitrate hexahydrate $\mathrm{Ni}\left(\mathrm{NO}_{3}\right)_{2} \cdot 6 \mathrm{H}_{2} \mathrm{O}$ was used as a Ni precursor; the latter was mixed with the UGSO in the targeted proportion. A small quantity of water was added, and the mixture was then milled and homogenized softly in a mortar at ambient temperature. The resulting milled mixture was oven-dried at $105^{\circ} \mathrm{C}$ for $4 \mathrm{~h}$ and then calcined at $900{ }^{\circ} \mathrm{C}$ for $12 \mathrm{~h}$. After calcination, the catalyst was sieved down to $53 \mu \mathrm{m}$ and was used in the catalytic tests as powder dispersed in the quartz wool placed in the differential reactor.

\subsubsection{Activation of Ni-UGSO}

The Ni-UGSO was activated by $\mathrm{H}_{2}$. The evolution of the catalyst structure was studied using TPR, TEM and XRD analysis. The catalyst was activated under a flow of $75 \% \mathrm{H}_{2}$ and $25 \% \mathrm{Ar}$ for a time-on-stream (TOS) of $2 \mathrm{~h}$. Table 11 shows the activation test conditions.

Table 11. Activation test conditions.

\begin{tabular}{ccccccc}
\hline Catalyst & $\begin{array}{c}\mathbf{H}_{2} \text { Flow Rate } \\
(\mathbf{m L} / \mathbf{m i n})^{\mathbf{a}}\end{array}$ & $\begin{array}{c}\text { Ar Flow Rate } \\
(\mathbf{m L} / \mathbf{m i n})^{\mathbf{a}}\end{array}$ & $\begin{array}{c}\text { Catalyst } \\
\text { Weight }(\mathrm{g})\end{array}$ & TOS (h) & $\begin{array}{c}\text { GHSV } \\
\left(\mathbf{m L}^{-1} \cdot \mathbf{g}^{-1}\right)\end{array}$ & T $\left({ }^{\circ} \mathbf{C}\right)$ \\
\hline $\begin{array}{c}\text { Ni-UGSO } \\
(\mathrm{wt} . \%=5,10,13)\end{array}$ & 30 & 10 & 0.5 & 2 & 4800 & 650 \\
\hline
\end{tabular}

\subsubsection{Dry Reforming (DR) and Catalytic Cracking (CC) Reactions}

Ni-UGSO was used as a catalyst for ethylene DR and CC. The influence of two factors was studied:

- Temperature;

- Weight percentage of $\mathrm{Ni}$ in the catalyst (wt.\%).

In order to choose the temperature range for the tests, a study of thermodynamic equilibrium was done at temperatures ranging from $350^{\circ} \mathrm{C}$ to $850^{\circ} \mathrm{C}$ (Section 2.3.1). The wt. $\%$ of $\mathrm{Ni}$ in the catalyst, $13 \%$, was chosen because the theoretical calculations based on the average UGSO composition show that 
this $\mathrm{Ni}$ content is necessary if all available $\mathrm{Fe}$ and $\mathrm{Al}$ oxides form spinels with $\mathrm{Ni}$ [30]. Nevertheless, since the catalytic activity comes from the local reduction of $\mathrm{Ni}$ and $\mathrm{Fe}$ into their metallic forms, as well as the concentration of these species at the surface of their support, lower Ni percentage were tested as well. Therefore, $10 \%$ and $5 \%$ were chosen arbitrarily as intermediate and lower wt.\% of $\mathrm{Ni}$.

A $3^{2}$ fully reproduced factorial design of experiments (18 runs) were conducted for each study (nine tests with their duplicates). The experiments were conducted at atmospheric pressure after the activation step. Reaction conditions are summarized in the Tables 12 and 13.

Table 12. Ethylene dry reforming (DR) reaction conditions.

\begin{tabular}{|c|c|c|c|c|c|c|}
\hline Catalyst & $\underset{(\mathrm{mL} / \mathrm{min})^{\mathrm{a}}}{\mathrm{C}_{2} \mathrm{H}_{4} \text { Flow Rate }}$ & $\begin{array}{c}\mathrm{CO}_{2} \text { Flow Rate } \\
(\mathrm{mL} / \mathrm{min})^{\mathrm{a}}\end{array}$ & $\begin{array}{l}\text { Catalyst } \\
\text { Weight (g) }\end{array}$ & TOS (h) & $\begin{array}{c}\text { GHSV } \\
\left(\mathrm{mL} \cdot \mathrm{h}^{-1} \cdot \mathrm{g}^{-1}\right)\end{array}$ & $\mathrm{T}\left({ }^{\circ} \mathrm{C}\right)$ \\
\hline $\begin{array}{c}\text { Ni-UGSO } \\
(\text { wt. } \%=5,10,13)\end{array}$ & 30 & 10 & 0.5 & 2 & 4800 & $550,650,750$ \\
\hline
\end{tabular}

Table 13. Ethylene catalytic cracking (CC) reaction conditions.

\begin{tabular}{|c|c|c|c|c|c|c|}
\hline Catalyst & $\begin{array}{c}\mathrm{C}_{2} \mathrm{H}_{4} \text { Flow Rate } \\
(\mathrm{mL} / \mathrm{min})^{\mathrm{a}}\end{array}$ & $\begin{array}{c}\text { Ar Flow Rate } \\
(\mathrm{mL} / \mathrm{min})^{a}\end{array}$ & $\begin{array}{c}\text { Catalyst } \\
\text { Weight (g) }\end{array}$ & TOS (h) & $\begin{array}{c}\text { GHSV } \\
\left(\mathrm{mL} \cdot \mathrm{h}^{-1} \cdot \mathrm{g}^{-1}\right)\end{array}$ & $\mathrm{T}\left({ }^{\circ} \mathrm{C}\right)$ \\
\hline $\begin{array}{c}\text { Ni-UGSO } \\
(\text { wt. } \%=5,10,13)\end{array}$ & 30 & 10 & 0.5 & 2 & 4800 & $550,650,750$ \\
\hline
\end{tabular}

\subsection{Characterization Techniques}

Several techniques were used to characterize fresh, activated, and spent catalysts. The information derived from the results of these techniques allows the understanding and interpretation of the phenomena that occur during the activation, DR, and CC reactions.

\subsubsection{XRD}

XRD analysis was used to identify fresh catalyst crystalline structure and to study transformations that might have occurred on this crystalline structure during and after activation, DR reactions, and CC reactions. The diffractometer used was Philips X'Pert PRO equipped with a Cu tube as its X-ray source and a Ni filter that was used to only let through $\mathrm{K} \alpha 1$ radiations from $\mathrm{Cu}(1.5418 \AA$ ) produced at $40 \mathrm{kV}$ and $50 \mathrm{~mA}$. The anti-dispersion slit was set at $1 / 2$ and the diverged slit at $1 / 4$. The analysis was carried out with a scanning angle of $2 \theta$ ranging from $15^{\circ}$ to $90^{\circ}$.

Crystallite size can be calculated using Scherrer Equation:

$$
\mathrm{L}_{\mathrm{c}}=\frac{\mathrm{K} \times \lambda}{\mathrm{d} \times \cos \theta}
$$

$\mathrm{L}_{\mathrm{c}}$-crystallite size $(\mathrm{nm})$;

$\mathrm{K}-0.9$;

$\lambda-1.5418$ ( $\AA$ ) for $\mathrm{Cu} \mathrm{K \alpha 1}$;

d-FHMW (full width at half maximum) calculated using Origin software (nm);

$\theta$-angle (rad).

\subsubsection{SEM and EDX}

Scanning electron microscopy was used to characterize CNF and to study their morphology. The microscope used was a Hitachi Cold FE SU-823000 characterized by a $0.5 \mathrm{~nm}$ resolution at 30 $\mathrm{kV}$ and $3 \mathrm{~nm}$ resolution at $0.05 \mathrm{kV}$. It was equipped with a secondary electron (SE) lower detector, an SE/backscattered electron (BSE) upper detector, an SE/BSE top detector with energy filtration of BSE, a five quadrant BSE detector, a STEM (scanning transmission electron microscopy) detector 
for bright/dark fields, and a drift silicon detector energy dispersive X-ray spectrometry (SDD-EDS) detector, which was used to study the elemental composition and mapping of the sample.

\subsubsection{TEM Coupled with EDX and Selected Area Electron Diffraction (SAED)}

The microscope used was the Jeol JEM-2100F analytical transmission electron microscope equipped with a field effect gun operating at an acceleration voltage of $200 \mathrm{kV}$. Capable of imaging resolutions of $0.1 \mathrm{~nm}$, this microscope was also equipped with an EDX spectrometer for chemical analysis. It also allowed the evaluation of crystallography using electron diffraction.

\subsubsection{TPR}

TPR was performed using a Chemisorb 2750 system (Micrometrics) equipped with a thermal conductivity detector (TCD). Tests were done after calibration of $\mathrm{H}_{2}$ consumption. Fifteen milligrams of the studied catalyst were put on quartz wool and deposited in the tube reactor. A gas mixture consisting of $10 \% v / v$ of $\mathrm{H}_{2}$ in Ar was fed in the TPR apparatus at a controlled flow rate of $40 \mathrm{~mL} / \mathrm{min}$. The sample was heated up to $1000{ }^{\circ} \mathrm{C}$ at a ramp rate of $2{ }^{\circ} \mathrm{C} / \mathrm{min}$ in a temperature-controlled oven. The sensor was put in a cold trap Dewar flask containing isopropanol in liquid nitrogen in order to protect it from $\mathrm{H}_{2} \mathrm{O}$ formed during reduction. ChemiSoft TCx software (Micromeritics) was used to calculate the peak area which is proportional to $\mathrm{H}_{2}$ consumption.

\subsubsection{TGA}

TGA was done using a Setaram Setsys 24 analyzer under $20 \% \mathrm{O}_{2}$ and $80 \%$ Ar in a temperature range between $20^{\circ} \mathrm{C}$ and $1000{ }^{\circ} \mathrm{C}$. For carbon deposited quantification, the TGA was carried out at a heating rate of $10^{\circ} \mathrm{C} / \mathrm{min}$.

\subsubsection{BET}

Specific surface area, pore volume, and pore average size were calculated by multipoint BET method. It was performed using an Accelerated Surface Area and Porosimetry System (ASAP 2020 V4.01).

\subsection{Reaction Metrics}

The performance of the catalyst was evaluated by calculating: $\mathrm{C}_{2} \mathrm{H}_{4}$ conversions $\left(\mathrm{X}_{\mathrm{C}_{2} \mathrm{H}_{4}}\right), \mathrm{H}_{2}$ yield $\left(Y_{H_{2}}\right)$, carbon yield $\left(Y_{C}\right)$, and carbon growth rate $\left(\mathrm{g}_{\mathrm{C}} \cdot \mathrm{g}_{\mathrm{cat}}{ }^{-1} \cdot \mathrm{h}^{-1}\right)$ in accordance with Algorithm 1 below:

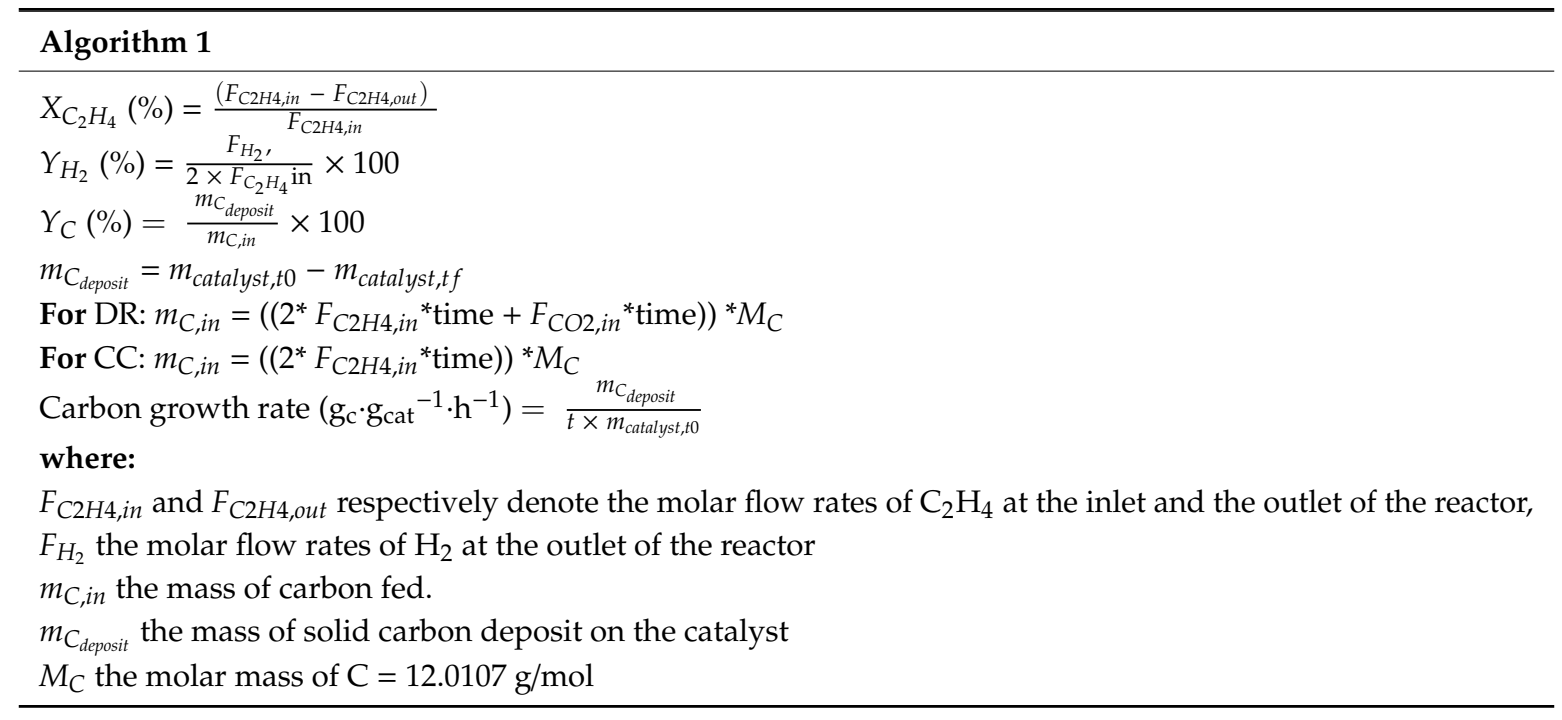




\section{Conclusions}

Ni-UGSO was prepared from a mining residue UGSO and then used to produce $\mathrm{CNF}$ and $\mathrm{H}_{2}$ via $\mathrm{CC}$ and DR reactions. When mining residues are involved in formulations, there is a concern regarding the variability of its composition. Prior to the present study and the ones published previously [30], four different batches of UGSO have been used to prepare the same catalytic formulations. The elemental analyses of the UGSO have shown that the variations were typically lower than $5 \%$ and the subsequent tests demonstrated that the observed conversion and yields deviations were lower than the overall experimental error and, consequently, not statistically significant.

$\mathrm{Ni}-\mathrm{UGSO} 13 \%$ at $750{ }^{\circ} \mathrm{C}$ for the CC reaction and at $650{ }^{\circ} \mathrm{C}$ for the DR reaction exhibited the best performance in terms of $\mathrm{H}_{2}$ and CNF yields. The literature has already provided the first insight into the factors influencing the formation of $\mathrm{CNF}$ and the mechanism of their formation, but the current work reveals the complexity of the latter. Although it is widely thought that the diameter of the CNF depends on the size of the catalyst particles, a more careful literature review along with the results of this work proves that other factors are also important. It has also been proven that carbides are the precursors of CNF and that the CNF-DR have higher structural order than CNF-CC. The type of CNF is also different. TEM images have shown that CNF-DR are fishbone shaped and CNF-CC form into tubular (MWNT) and stacked-cup structures. The results show that $\mathrm{Fe}$ is the main precursor of the $\mathrm{CNF}$ growth while $\mathrm{Ni}$ is more contributing to the split of $\mathrm{C}-\mathrm{C}$ bonds. In terms of conversion and yield efficiencies, the performance of the catalytic formulations tested is proven at least equivalent to other $\mathrm{Ni}$-based catalyst performances described by the literature. The experiments reported were conducted in a lab scale (g-lab) fixed-bed reactor and serve as a preliminary study. Ongoing work focuses on the production of $\mathrm{CNF}$ and $\mathrm{H}_{2}$ in a kg-lab scale fluidized bed reactor to prove the feasibility at a larger scale towards eventual process commercialization.

Author Contributions: A.A.: PhD student whose topic is directly related to the content of this manuscript. She has written the first draft of the manuscript. E.-H.B. and F.M.: Professors who co-supervise the scientific part of the PhD project. They have read and corrected the manuscript. M.C.: Post-doctoral fellow who has helped and provided guidance during the experimentation. F.G.: Professor who co-supervise the scientific part of the PhD project. He has read and commented the manuscript. N.A.: Professor who co-supervise the PhD work and he is the scientific and technical Director of the Research team and the overall project. He has defined the content of the manuscript, read, corrected and proofread all intermediate steps until final acceptance.

Funding: The authors are indebted to the Natural Sciences and Engineering Research Council (NSERC) of Canada (RDCPJ-500331-16), PRIMA-Quebec (R10-010), and to the industrial partners for providing project's funding. They would also like to thank Gilles L'Espérance, Raynald Gauvin, Nicolas Brodusch, and Jean-Philippe Masse for the assistance provided in terms of TEM analyses. Special thanks are due to Jasmin Blanchard for his scientific and technical contributions to this manuscript, and to all the instrumental specialists at the CCM of the Université de Sherbrooke for the TPR, SEM, and XRD analyses.

Conflicts of Interest: There are no conflicts of interest to declare.

\section{References}

1. Baker, R.T.K.; Gadsby, G.R.; Thomas, R.B.; Waite, R.J. The production and properties of filamentous carbon. Carbon 1975, 13, 211-214. [CrossRef]

2. Baker, R.T.K. Carbon Nanofibers. In Reference Module in Materials Science and Materials Engineering; Elsevier: Amsterdam, The Netherlands, 2016; ISBN 978-0-12-803581-8.

3. Albright, L.F.; Baker, R.T.K. (Eds.) Coke Formation on Metal Surfaces; ACS Symposium Volume 202; American Chemical Society: Washington, DC, USA, 1983; ISBN 978-0-8412-0745-5.

4. Jankhah, S.; Abatzoglou, N.; Gitzhofer, F.; Blanchard, J.; Oudghiri-Hassani, H. Catalytic properties of carbon nano-filaments produced by iron-catalysed reforming of ethanol. Chem. Eng. J. 2008, 139, 532-539. [CrossRef]

5. Zeng, J.; Saltysiak, B.; Johnson, W.S.; Schiraldi, D.A.; Kumar, S. Processing and properties of poly(methyl methacrylate)/carbon nano fiber composites. Compos. Part B Eng. 2004, 35, 173-178. [CrossRef]

6. Tao, X.Y.; Zhang, X.B.; Zhang, L.; Cheng, J.P.; Liu, F.; Luo, J.H.; Luo, Z.Q.; Geise, H.J. Synthesis of multi-branched porous carbon nanofibers and their application in electrochemical double-layer capacitors. Carbon 2006, 44, 1425-1428. [CrossRef] 
7. Ji, L.; Lin, Z.; Medford, A.J.; Zhang, X. Porous carbon nanofibers from electrospun polyacrylonitrile/SiO2 composites as an energy storage material. Carbon 2009, 47, 3346-3354. [CrossRef]

8. Yoon, S.H.; Park, C.W.; Yang, H.; Korai, Y.; Mochida, I.; Baker, R.T.K.; Rodriguez, N.M. Novel carbon nanofibers of high graphitization as anodic materials for lithium ion secondary batteries. CARBON 2004, 42, 21-32. [CrossRef]

9. Fauteux-Lefebvre, C.; Abatzoglou, N.; Blais, S.; Braidy, N.; Hu, Y. Iron oxide-functionalized carbon nanofilaments for hydrogen sulfide adsorption: The multiple roles of carbon. Carbon 2015, 95, 794-801. [CrossRef]

10. Bezemer, G.L.; Radstake, P.B.; Koot, V.; van Dillen, A.J.; Geus, J.W.; de Jong, K.P. Preparation of Fischer-Tropsch cobalt catalysts supported on carbon nanofibers and silica using homogeneous deposition-precipitation. J. Catal. 2006, 237, 291-302. [CrossRef]

11. Mestl, G.; Maksimova, N.I.; Keller, N.; Roddatis, V.V.; Schlögl, R. Carbon Nanofilaments in Heterogeneous Catalysis: An Industrial Application for New Carbon Materials? Angew. Chem. Int. Ed. 2001, 40, 2066-2068. [CrossRef]

12. Bockris, J.O.M. The hydrogen economy: Its history. Int. J. Hydrog. Energy 2013, 38, 2579-2588. [CrossRef]

13. Wei, Z.; Sun, J.; Li, Y.; Datye, A.K.; Wang, Y. Bimetallic catalysts for hydrogen generation. Chem. Soc. Rev. 2012, 41, 7994-8008. [CrossRef] [PubMed]

14. Blanchard, J.; Oudghiri-Hassani, H.; Abatzoglou, N.; Jankhah, S.; Gitzhofer, F. Synthesis of nanocarbons via ethanol dry reforming over a carbon steel catalyst. Chem. Eng. J. 2008, 143, 186-194. [CrossRef]

15. Jankhah, S.; Abatzoglou, N.; Gitzhofer, F. Thermal and catalytic dry reforming and cracking of ethanol for hydrogen and carbon nanofilaments' production. Int. J. Hydrog. Energy 2008, 33, 4769-4779. [CrossRef]

16. Chamoumi, M.; Abatzoglou, N. NiFe2O4 production from $\alpha-\mathrm{Fe} 2 \mathrm{O} 3$ via improved solid state reaction: Application as catalyst in CH4 dry reforming. Can. J. Chem. Eng. 2016, 94, 1801-1808. [CrossRef]

17. Braidy, N.; Bastien, S.; Blanchard, J.; Fauteux-Lefebvre, C.; Achouri, I.E.; Abatzoglou, N. Activation mechanism and microstructural evolution of a YSZ/Ni-alumina catalyst for dry reforming of methane. Catal. Today 2017, 291, 99-105. [CrossRef]

18. Shah, Y.T.; Gardner, T.H. Dry Reforming of Hydrocarbon Feedstocks. Catal. Rev. 2014, 56, 476-536. [CrossRef]

19. Pinilla, J.L.; Utrilla, R.; Lázaro, M.J.; Moliner, R.; Suelves, I.; García, A.B. Ni- and Fe-based catalysts for hydrogen and carbon nanofilament production by catalytic decomposition of methane in a rotary bed reactor. Fuel Process. Technol. 2011, 92, 1480-1488. [CrossRef]

20. $\mathrm{Hu}, \mathrm{X}$; $\mathrm{Lu}, \mathrm{G}$. Syngas production by $\mathrm{CO} 2$ reforming of ethanol over Ni/Al2O3 catalyst. Catal. Commun. 2009, 13, 1633-1637. [CrossRef]

21. Takehira, K.; Ohi, T.; Shishido, T.; Kawabata, T.; Takaki, K. Catalytic growth of carbon fibers from methane and ethylene on carbon-supported Ni catalysts. Appl. Catal. A Gen. 2005, 283, 137-145. [CrossRef]

22. Nakagawa, K.; Nishitani-Gamo, M.; Ogawa, K.; Ando, T. Catalytic growth of carbon nanofilament in liquid hydrocarbon. Catal Lett 2005, 101, 191-194. [CrossRef]

23. Pinilla, J.L.; de Llobet, S.; Moliner, R.; Suelves, I. Ni-Co bimetallic catalysts for the simultaneous production of carbon nanofibres and syngas through biogas decomposition. Appl. Catal. B Environ. 2017, 200, 255-264. [CrossRef]

24. Arena, U.; Mastellone, M.L.; Camino, G.; Boccaleri, E. An innovative process for mass production of multi-wall carbon nanotubes by means of low-cost pyrolysis of polyolefins. Polym. Degrad. Stab. 2006, 91, 763-768. [CrossRef]

25. Svinterikos, E.; Zuburtikudis, I. Carbon nanofibers from renewable bioresources (lignin) and a recycled commodity polymer [poly(ethylene terephthalate)]. J. Appl. Polym. Sci. 2016, 133. [CrossRef]

26. Krylov, O.V.; Mamedov, A.K.; Mirzabekova, S.R. Oxidation of Hydrocarbons and Alcohols by Carbon Dioxide on Oxide Catalysts. Ind. Eng. Chem. Res. 1995, 34, 474-482. [CrossRef]

27. Baker, R.T.K.; Alonzo, J.R.; Dumesic, J.A.; Yates, D.J.C.J. Effect of the surface state of iron on filamentous carbon formation. J. Catal. 1982, 77, 74-84. [CrossRef]

28. Nguyen, H.N.T.; Berguerand, N.; Thunman, H. Mechanism and Kinetic Modeling of Catalytic Upgrading of a Biomass-Derived Raw Gas: An Application with Ilmenite as Catalyst. Ind. Eng. Chem. Res. 2016, 55, 5843-5853. [CrossRef] 
29. Romero, A.; Garrido, A.; Nieto-Márquez, A.; Sánchez, P.; de Lucas, A.; Valverde, J.L. Synthesis and structural characteristics of highly graphitized carbon nanofibers produced from the catalytic decomposition of ethylene: Influence of the active metal (Co, Ni, Fe) and the zeolite type support. Microporous Mesoporous Mater. 2008, 110, 318-329. [CrossRef]

30. Chamoumi, M.; Abatzoglou, N.; Blanchard, J.; Iliuta, M.-C.; Larachi, F. Dry reforming of methane with a new catalyst derived from a negative value mining residue spinellized with nickel. Catal. Today 2017, 291, 86-98. [CrossRef]

31. Bali, A.; Blanchard, J.; Chamoumi, M.; Abatzoglou, N. Bio-Oil Steam Reforming over a Mining Residue Functionalized with Ni as Catalyst: Ni-UGSO. Catalysts (2073-4344) 2018, 8, 1-24.

32. Yu, Z.; Chen, D.; Tøtdal, B.; Holmen, A. Parametric study of carbon nanofiber growth by catalytic ethylene decomposition on hydrotalcite derived catalysts. Mater. Chem. Phys. 2005, 92, 71-81. [CrossRef]

33. Chesnokov, V.V.; Buyanov, R.A. The formation of carbon filaments upon decomposition of hydrocarbons catalysed by iron subgroup metals and their alloys. Russ. Chem. Rev. 2000, 69, 623-638. [CrossRef]

34. Díaz, M.C.; Blackman, J.M.; Snape, C.E. Maximising carbon nanofiber and hydrogen production in the catalytic decomposition of ethylene over an unsupported Ni-Cu alloy. Appl. Catal. A Gen. 2008, 339, $196-208$.

35. Ermakova, M.A.; Ermakov, D.Y.; Chuvilin, A.L.; Kuvshinov, G.G. Decomposition of Methane over Iron Catalysts at the Range of Moderate Temperatures: The Influence of Structure of the Catalytic Systems and the Reaction Conditions on the Yield of Carbon and Morphology of Carbon Filaments. J. Catal. 2001, 201, 183-197. [CrossRef]

36. Sacco, A.; Thacker, P.; Chang, T.N.; Chiang, A.T.S. The initiation and growth of filamentous carbon from $\alpha$-iron in $\mathrm{H} 2, \mathrm{CH} 4, \mathrm{H} 2 \mathrm{O}, \mathrm{CO} 2$, and CO gas mixtures. J. Catal. 1984, 85, 224-236. [CrossRef]

37. Pang, L.S.K.; Saxby, J.D.; Chatfield, S.P. Thermogravimetric analysis of carbon nanotubes and nanoparticles. J. Phys. Chem. 1993, 97, 6941-6942. [CrossRef]

38. Pradhan, D.; Sharon, M. Carbon nanotubes, nanofilaments and nanobeads by thermal chemical vapor deposition process. Mater. Sci. Eng. B 2002, 96, 24-28. [CrossRef]

39. Sui, Y.C.; Acosta, D.R.; González-León, J.A.; Bermúdez, A.; Feuchtwanger, J.; Cui, B.Z.; Flores, J.O.; Saniger, J.M. Structure, Thermal Stability, and Deformation of Multibranched Carbon Nanotubes Synthesized by CVD in the AAO Template. J. Phys. Chem. B 2001, 105, 1523-1527. [CrossRef]

40. Serp, P.; Corrias, M.; Kalck, P. Carbon nanotubes and nanofibers in catalysis. Appl. Catal. A Gen. 2003, 253, 337-358. [CrossRef]

41. Narkiewicz, U.; Podsiadły, M.; Jędrzejewski, R.; Pełech, I. Catalytic decomposition of hydrocarbons on cobalt, nickel and iron catalysts to obtain carbon nanomaterials. Appl. Catal. A Gen. 2010, 384, 27-35. [CrossRef]

42. Lander, J.J.; Kern, H.E.; Beach, A.L. Solubility and Diffusion Coefficient of Carbon in Nickel: Reaction Rates of Nickel-Carbon Alloys with Barium Oxide. J. Appl. Phys. 1952, 23, 1305-1309. [CrossRef]

43. Park, C.; Baker, R.T.K. Carbon Deposition on Iron-Nickel During Interaction with Ethylene-Carbon Monoxide-Hydrogen Mixtures. J. Catal. 2000, 190, 104-117. [CrossRef]

44. Koestner, R.J.; Frost, J.C.; Stair, P.C.; Van Hove, M.A.; Somorjai, G.A. Evidence for the formation of stable alkylidyne structures from C3 and C4 unsaturated hydrocarbons adsorbed on the pt(111) single crystal surface. Surf. Sci. 1982, 116, 85-103. [CrossRef]

45. Zhu, X.-Y.; White, J.M. Interaction of ethylene and acetylene with Ni(111): A SSIMS study. Surf. Sci. 1989, 214, 240-256. [CrossRef]

46. Rodriguez, N.M. A review of catalytically grown carbon nanofibers. J. Mater. Res. 1993, 8, 3233-3250. [CrossRef]

47. Chitrapu, P.; Lund, C.R.F.; Tsamopoulos, J.A. A model for the catalytic growth of carbon filaments. Carbon 1992, 30, 285-293. [CrossRef]

48. Audier, M.; Coulon, M.; Oberlin, A. Relative crystallographic orientations of carbon and metal in a filamentous catalytic carbon. Carbon 1980, 18, 73-76. [CrossRef]

49. Nolan, P.E.; Lynch, D.C.; Cutler, A.H. Carbon Deposition and Hydrocarbon Formation on Group VIII Metal Catalysts. J. Phys. Chem. B 1998, 102, 4165-4175. [CrossRef]

50. Luo, J.Z.; Yu, Z.L.; Ng, C.F.; Au, C.T. CO2/CH4 Reforming over Ni-La2O3/5A: An Investigation on Carbon Deposition and Reaction Steps. J. Catal. 2000, 194, 198-210. [CrossRef]

51. Krishnankutty, N.; Rodriguez, N.M.; Baker, R.T.K. Effect of Copper on the Decomposition of Ethylene over an Iron Catalyst. J. Catal. 1996, 158, 217-227. [CrossRef] 
52. Baker, R.T.K.; Barber, M.A.; Harris, P.S.; Feates, F.S.; Waite, R.J. Nucleation and growth of carbon deposits from the nickel catalyzed decomposition of acetylene. J. Catal. 1972, 26, 51-62. [CrossRef]

53. Oberlin, A.; Endo, M.; Koyama, T. Filamentous growth of carbon through benzene decomposition. J. Cryst. Growth 1976, 32, 335-349. [CrossRef]

(C) 2019 by the authors. Licensee MDPI, Basel, Switzerland. This article is an open access article distributed under the terms and conditions of the Creative Commons Attribution (CC BY) license (http://creativecommons.org/licenses/by/4.0/). 